\title{
A Breath of Fresh Air \\ Abstracts from the 1st Canadian Respiratory Conference
}

\author{
June 19-21, 2008 \\ Montreal, Quebec
}

ASTHMA / CHRONIC OBSTRUCTIVE

PULMONARY DISEASE (COPD) STREAM

1

THE INTERACTION OF BODY MASS INDEX (BMI) AND

MEDICATION ADHERENCE ON ASTHMA CONTROL

Simon L Bacon ${ }^{1,2}$, Kim L Lavoie ${ }^{1,3}$

${ }^{1}$ Montreal Behavioural Medicine Center, Hôpital du Sacré-Coeur de Montreal; ${ }^{2}$ Department of Exercise Science, Concordia University; ${ }^{3}$ Department of Psychology, University of Quebec at Montreal (UQAM), Montreal, Quebec

Both a high BMI and poor medication adherence are examples of poor selfregulatory behaviours. Both have been shown to reduce asthma control, though little is known about the extent to which they interact to worsen asthma control. This study assessed the interaction of BMI and medication adherence on asthma control in 359 adult patients $(58 \%$ women, mean age $=$ 47 years). All patients underwent a sociodemographic and medical interview (including self-reported inhaled corticosteroid [ICS] adherence, height and weight), completed the Asthma Control Questionnaire, and underwent pulmonary function testing on the day of their asthma clinic visit. BMI was categorized as normal, overweight, and obese using standard definitions. Adherence was categorized as taking ICS medications as prescribed (73\%) vs. not as prescribed (i.e., never, more and less than prescribed: $27 \%$ ). For patients reporting taking their ICS medication as prescribed, they estimated the \% of time they took them as prescribed $($ mean $=96.7 \%)$. General linear models $($ GLM) revealed a main effect of the binary adherence variable $(\mathrm{F}=12.3, \mathrm{p}<.001)$, a trend for BMI $(\mathrm{F}=2.63, \mathrm{p}=.074)$ and no interaction effect $(\mathrm{F}=0.55, \mathrm{p}=.577)$, such that patients who did not take their ICS medications as prescribed had worse control and patients with higher BMI's tended to have worse control. A second GLM revealed a main effect of BMI $(F=2.38, p=.018)$ but no main effect of $\%$ of time ICS medications were taken as prescribed $(\mathrm{F}=0.19, \mathrm{p}=.853)$, however, there was a significant interaction $(\mathrm{F}=-2.31, \mathrm{p}=.022)$ such that worse control was associated with increasing BMI in those who did not take their ICS medications as prescribed. All analyses controlled for age, sex, and asthma severity. In spite of the limitations in the measure of adherence used, there was an interaction between adherence and BMI, indicating that both of these variables should be targeted to improve asthma control.

Financial support: Grant and salary support was provided from the Fonds de la recherche en santé du Québec (FRSQ)

\section{2}

WHAT FACTORS ARE ASSOCIATED WITH SUICIDAL IDEATION IN ASTHMA PATIENTS?

H Favreau, SL Bacon, A Rizk, A Bouchard, M Joseph, M Piccioni, M Labrecque, KL Lavoie

Montreal Behavioural Medicine Centre, Hôpital du Sacré-Cour de Montréal; Psychology, Université du Québec à Montréal (UQAM); Exercise Science, Concordia University; Psychology, McGill University; Montreal, Quebec

BACKGROUND: Asthma is a chronic respiratory disease that has been previously associated with a disproportionately high level of suicidal ideation (SI), independent of depression. However, the precise mechanisms linking asthma to suicidal ideation remain poorly understood. Several asthma medications like theophylline and beta-2 adrenergic-agnonists (which are potent bronchodilators), have been shown to provoke intense feelings of anxiety, fear, or panic in some individuals. These drugs may potentially influence rates of SI in asthma patients, but this has yet to be explored. The present study assessed SI in 630 consecutive adult asthma patients presenting to an outpatient clinic $(40 \%$ men; mean age $=50 \mathrm{yrs})$.
METHODS: All patients underwent a sociodemographic, psychiatric (PRIME-MD), and medical history interview, and completed a battery of questionnaires including the Beck Depression Inventory-II (BDI-II) and Asthma Control Questionnaire (ACQ). Responses $\geq 1$ on question 9 of the BDI were used to measure SI.

RESULTS: BDI-II results indicated that $12 \%$ of asthmatics reported having SI. After controlling for age, sex, smoking status, and major depression, results of general linear model analyses indicated a significant main effect theophylline use $(\mathrm{F}=3.85, \mathrm{p}<.05)$, but not beta-2 agonist use $(\mathrm{F}=0.04$, $\mathrm{p}=.8497)$, on SI. Though asthma control and severity levels were also significantly associated with SI in univariate analyses, these associations were no longer significant after controlling for covariates.

CONCLUSIONS: These findings suggest that theophylline use may be associated with a higher risk of SI in adult asthmatics. It is noteworthy that these findings were independent of major depression, which suggests results are not simply the results of depressive symptomatology in asthma patients. Clinically, these findings indicate that physicians should be vigilant about the potential psychological side effects of certain asthma medications, particularly those that enhance central nervous system activity.

Funding: Operating and personal support (HF, SLB, KLL) support was obtained from fonds de recherche en sante du Quebec (FRSQ) and Institut de recherche en santé et sécurité au travail (IRSST)

\section{3}

\section{IDENTIFYING PATIENTS DIAGNOSED WITH ASTHMA USING HEALTH ADMINISTRATIVE DATA} Andrea Gershon MD MSc FRCPC ${ }^{1,2,3}$, Chengning Wang MD MSc ${ }^{1}$, Jovanka Vasilevska-Ristovska MD ${ }^{1}$, Juan Guan MSc $^{3}$, Lisa Cicutto PhD ACNP CAE ${ }^{2}$, Teresa To $\mathrm{PhD}^{1,2,3}$

${ }^{1}$ The Hospital For Sick Children; ${ }^{2}$ University of Toronto; ${ }^{3}$ Institute for Clinical Evaluative Sciences, Toronto, Ontario

RATIONALE: The Ontario Asthma Surveillance Information System uses health administrative data to provide province-wide population surveillance. To accurately identify individuals diagnosed with asthma using such data, a case verification study was conducted.

METHODS: Individuals aged 19 to 80 years with $(n=160)$ or without asthma $(\mathrm{n}=358)$ were randomly selected from 13 primary care practices across Ontario, Canada. Their medical records were abstracted and interpreted by a panel of pulmonologists to establish a gold standard diagnosis. This diagnosis was linked to each individual's respective health administrative database records and compared with various claim algorithms. The test characteristics of the claim algorithms were calculated and compared. RESULTS:

Test Characteristics of Algorithms for Asthma

\begin{tabular}{|c|c|c|c|c|c|}
\hline $\begin{array}{l}\text { Algorithm (Number } \\
\text { and type of claims) }\end{array}$ & $\begin{array}{l}\text { Time period } \\
\text { (years) }\end{array}$ & Sn (\%) & Sp (\%) & PPV (\%) & NPV (\%) \\
\hline $\begin{array}{l}\geq 1 \text { outpatient claim or } \\
\geq 1 \text { hospitalization }\end{array}$ & unspecified & 95.0 & 59.2 & 51.0 & 96.4 \\
\hline \multirow{2}{*}{$\begin{array}{l}\geq 2 \text { outpatient claims or } \\
\geq 1 \text { hospitalization }\end{array}$} & 2 & 83.8 & 76.5 & 61.5 & 91.3 \\
\hline & 3 & 85.0 & 75.1 & 60.4 & 91.8 \\
\hline \multirow{2}{*}{$\begin{array}{l}\geq 3 \text { outpatient claims or } \\
\geq 1 \text { hospitalization }\end{array}$} & 2 & 76.9 & 84.4 & 68.7 & 89.1 \\
\hline & 3 & 60.2 & 96.1 & 81.0 & 89.6 \\
\hline
\end{tabular}

NPV Negative predictive value; PPV Positive predictive value; Sn Sensitivity; Sp Specificity

CONCLUSIONS: Our results suggest that a health service use based algorithm can accurately identify individuals with asthma for on-going surveillance. An algorithm of $\geq 2$ outpatient claims or $\geq 1$ hospitalization 
attributable to asthma in a 2-year period yields the best test characteristics and is most practical to use for this purpose.

Funded by: Ontario Ministry of Health and Long-Term Care

4

WHAT IS THE RISK OF DEVELOPING ASTHMA IN THE FIRST 40 YEARS OF LIFE?

Teresa To $\mathrm{PhD}^{1,2,3}$, Chengning Wang MD MSc${ }^{1}$, Juan Guan MSc ${ }^{3}$, Andrea Gershon MD MSc FRCPC 1,2,3

${ }^{1}$ The Hospital For Sick Children; ${ }^{2}$ University of Toronto; ${ }^{3}$ Institute for Clinical Evaluative Sciences, Toronto, Ontario

RATIONALE: Estimates of cumulative risk of developing asthma provide valuable measures to help researchers set research agendas, predict the burden of asthma on society; and health planners target the most vulnerable population for asthma prevention, management and control.

METHODS: Cross-sectional age- and sex-specific asthma incidence rates in 2001 were calculated using the population-based asthma cohort assembled by the Ontario Asthma Surveillance Information System. These rates were applied to a life table stationary population of Ontario in 1995-97 to generate the number of asthma incident cases by age and sex. The probabilities of being diagnosed with asthma from birth to age 39 years were estimated using the Actuarial Life Table Method.

RESULTS: The cumulative risk of developing asthma from birth to age 39 years was $41.2 \%$. Overall, males had a $2 \%$ higher cumulative risk compared to females $(42.3 \%$ versus $40.2 \%, \mathrm{p}<0.05)$.

Cumulative Risk of Developing Asthma before Age 40 Years

\begin{tabular}{lccccccc}
\hline $\begin{array}{l}\text { Age } \\
\text { (years) }\end{array}$ & $\begin{array}{c}\text { Birth } \\
\mathbf{0}\end{array}$ & $\begin{array}{c}\text { School } \\
\text { age }\end{array}$ & $\begin{array}{c}\text { Early } \\
\text { Adolescence }\end{array}$ & $\mathbf{1 2}$ & $\begin{array}{c}\text { Late } \\
\text { adolescence }\end{array}$ & \multicolumn{2}{c}{ Early } \\
adulthood & Adulthood & \\
\hline $\begin{array}{l}\text { Overall risk } \\
\quad \text { (\%) }\end{array}$ & 41.2 & 25.9 & 20.0 & 16.0 & 12.3 & 8.2 & 3.5 \\
Male (\%) & 42.3 & 23.4 & 16.4 & 12.8 & 10.1 & 6.7 & 2.7 \\
Female (\%) & 40.2 & 28.1 & 23.3 & 19.0 & 14.5 & 9.6 & 4.1
\end{tabular}

CONCLUSIONS: At least 2 out of every 5 people develop asthma at some point in their lives. This means that just less than half of the population is likely to receive medical attention for asthma. It also suggests significant lost productivity and economic costs due to asthma. More research is needed to identify the causes of asthma for prevention and effective asthma programs for treatment, management and education to ensure that individuals with asthma will continue to live and function with good quality of life.

Funded by: Ontario Ministry of Health and Long-Term Care

\section{5}

\section{ESTIMATING THE BURDEN OF COMORBIDITY ON INDIVIDUALS WITH ASTHMA}

Andrea Gershon MD MSc FRCPC ${ }^{1,2,3}$, Chengning Wang MD MSc ${ }^{1}$, Jovanka Vasilevska-Ristovska MD ${ }^{1}$, Juan Guan MSc $^{3}$,

Teresa To $\mathrm{PhD}^{1,2,3}$

${ }^{1}$ The Hospital For Sick Children; ${ }^{2}$ University of Toronto; ${ }^{3}$ Institute for Clinical Evaluative Sciences, Toronto, Ontario

RATIONALE: Asthma is a highly prevalent disease associated with many conditions (e.g. respiratory tract infection and atopy). This study compared the burden of non-asthma ambulatory care claims on individuals with and without asthma.

METHODS: All individuals in Ontario between 2000 and 2004 were included. A diagnosis of asthma was made using health administrative data. Age and sex standardized all-cause, asthma-specific and asthmaassociated ambulatory care claim rates (including claims for physician services and testing) were estimated and compared between individuals with and without asthma. Asthma-associated claims included respiratory and atopic conditions that may exacerbate or be exacerbated by asthma.

RESULTS: In 2004, 12.7\% (N=1,603,142) of people aged 0-99 years in Ontario had asthma. Individuals with asthma had 889,421 claims for asthma, 2,652,788 claims for asthma-associated conditions, and 18,803,134 claims for other conditions; while individuals without asthma $(\mathrm{N}=11,050,539)$ had $8,877,785$ claims for asthma-associated conditions, and 104,093,432 claims for other conditions.

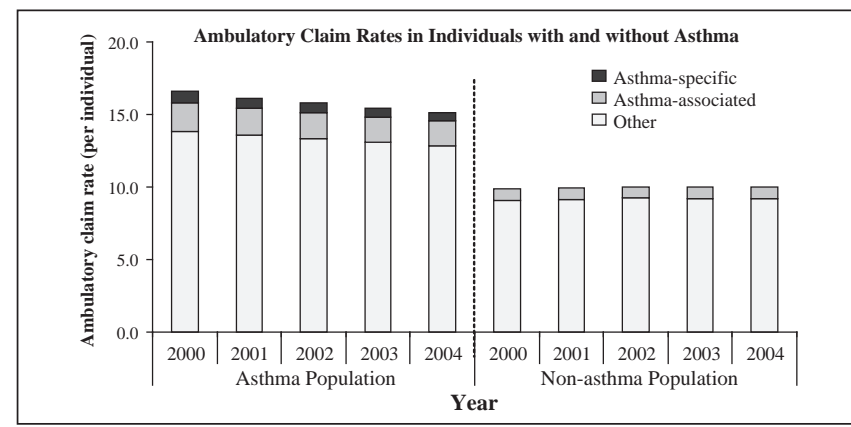

CONCLUSIONS: In individuals with asthma, asthma associated comorbidity appears to be the cause of more claims than asthma. Respiratory and atopic conditions make up a significant proportion of the comorbidity burden; however, a large part remains unexplained.

Funded by: Ontario Ministry of Health and Long-Term Care

\section{6}

\section{DEVELOPING A PROVINCIAL ALBERTA ASTHMA ACTION} PLAN (AAAP)

Shawna McGhan RN, Eileen Gresl, Heather Sharpe RN, Warren Davidson MD, Robert Hauptman MD, Thelma Oribello RN, Roberta Dubois RRT, Dean Befus PhD, Sheldon Spier MD, COPD \& Asthma Network of Alberta (CANA) Task Force

University of Alberta, Edmonton; University of Calgary, Calgary, Alberta

PURPOSE: To develop a standardized written asthma action plan (AP) to address provincial care inconsistencies and promote better patient self-management.

METHODS: In CANA's survey of 392 Canadian practitioners (90 from Alberta), half the respondents felt that multiple AP formats cause confusion for asthma patients and $69 \%$ believed that a standardized written AP would increase their use. A 12-member multidisciplinary Task Force identified Canada's most marketed/evaluated AP versions and objectively selected the one most closely matching respondents' requirements, supported by best evidence and practical experience. Quebec Asthma Education Network's AP met many of the criteria and was adapted (with permission). Following 1 year of development, the AAAP was piloted by 36 health professionals (nurses, RRTs, and FPs) at 8 sites around the province (4 rural, 4 urban).

RESULTS: Pilot participants completed a 2-page post survey. Response rate was $33 \%$. Results showed the AAAP was useful for both adults and children, eliminating our intention to tailor 2 separate AAAP's. $75 \%$ of respondents agreed that the AAAP had a patient friendly design, was easy to fill out, simplified patient directions, and that it would impact patient control. 66\% said they would continue to use the AAAP, despite needed improvements. From a list options, respondents strongly supported dissemination through FPs, Pharmacists, and the public using colour triplicate tear-off non-carbon pads and fillable PDF as preferred formats. These results have led to further AAAP refinement and applications for study grants.

IMPLICATIONS: A provincially approved standardized AP was successfully developed for Alberta and is undergoing evaluation to determine its impact. Financial support provided by CANA, The Lung Association of AB/NWT, and Family Physician Airways Group of Canada

\section{7}

\section{DOES SMOKING AND A HIGHER BMI EXPLAIN THE RELATIONSHIP BETWEEN DEPRESSION AND POOR ASTHMA CONTROL?}

Maryann F Joseph, Simon L Bacon, Deborah A Samek, Blaine Ditto, Kim L Lavoie

Montreal Behavioural Medicine Centre, Hôpital du Sacré-Coeur; Psychology, McGill University; Exercise Science, Concordia University; Psychology, Université du Quebéc à Montréal (UQAM); Montreal, Quebec

Depression and asthma are two highly prevalent contributors to the personal and socioeconomic burden of illness in Canada. Among adult 
asthmatics, co-morbid major depression has been associated with worse asthma control. Depression has been associated with smoking and elevated body mass index (BMI), both of which have a negative impact upon respiratory health. However, little is known about whether smoking and obesity mediate the association between depression and poor asthma control. 518 patients with documented asthma (41\% men; $\mathrm{M}$ age $50 \mathrm{yrs}$ ) underwent a sociodemographic, medical, and psychiatric (PRIME-MD) interview and completed a battery of questionnaires, including the Asthma Control Questionnaire (ACQ), on the day of their asthma clinic visit. All patients underwent pulmonary function testing. General linear model analyses indicated that asthmatic patients with major depression had significantly worse asthma control than those with no mood disorder $(F=22.70$, $\mathrm{p}<.001$ ), controlling for covariates: age, sex, asthma severity, asthma duration, co-morbid anxiety disorders, and treatment by a mental health professional. Depression was not related to smoking status (current, previous, and never; $\mathrm{F}=0.11, \mathrm{p}=.739)$ or $\mathrm{BMI}(\mathrm{F}=0.29, \mathrm{p}=.590)$. However, smoking status $(\mathrm{F}=10.04, \mathrm{p}=.002)$ and $\mathrm{BMI}(\mathrm{F}=10.46, \mathrm{p}=.001)$ were significantly associated with poorer asthma control. When smoking status and BMI were included in the analyses, major depression was still related to poorer asthma control $(\mathrm{F}=11.65, \mathrm{p}=.001)$. Results suggest that asthma patients with co-morbid major depression may have worse asthma control than those with no mood disorder, but that smoking status and BMI do not explain this relationship. While health behaviours (smoking, overeating, not exercising) may play an important role in asthma control, they do not appear to account for depression's impact on levels of asthma control. Grant funding: Fonds de la recherche en santé du Québec (FRSQ) - KL EB SB; Institut Robert-Sauvé en santé et en sécurité du travail (IRSST) - KL; Scholarship support: Social Sciences and Humanities Research Council (SSHRC) - MJ; Institut Robert-Sauvé en santé et en sécurité du travail (IRSST) - MJ

\section{8}

\section{IS SOCIO-ECONOMIC STATUS ASSOCIATED WITH WORSE ASTHMA CONTROL AND HEALTH SERVICE UTILIZATION IN ADULT ASTHMATICS?}

Kim L Lavoie ${ }^{1,2,3}$, Anne Bouchard ${ }^{1,2,3}$, Isabelle Boisvert ${ }^{1,2,3}$, Eric Loucks ${ }^{1,4}$, Simon L Bacon ${ }^{1,3,5}$

${ }^{1}$ Montreal Behavioral Medicine Center; ${ }^{2}$ Dept of Psychology, University of Quebec at Montreal (UQAM); ${ }^{3}$ Chest Medicine, Hôpital du Sacré-Coeur de Montreal; ${ }^{4}$ Epidemiology, McGill University; ${ }^{5}$ Department of Exercise Science, Concordia University, Montreal, Quebec

Socio-economic status (SES) has been linked to higher morbidity in patients with several chronic diseases, but may be particularly relevant to asthma due to mechanisms by which it could adversely impact asthma outcomes. At the individual level, asthmatics with a lower SES may have higher exposures to indoor (e.g., cockroaches, tobacco smoke) and outdoor (e.g., urban pollution) allergens, and poorer access to health care, which may increase risk for exacerbations. Though the SES-asthma link has been well established in children, less is known about this association in adults. This study assessed associations between adult SES and several measures of asthma morbidity in 782 adult asthmatics including: asthma control; pulmonary function $\left(\% \mathrm{FEV}_{1}\right)$; asthma-related health service use in the past year (emergency department, ED visits and hospitalizations); asthma selfefficacy, and asthma-related quality of life. The sample included 467 women with a mean age of 48.5 yrs. All patients underwent a sociodemographic and medical history interview and pulmonary function testing on the day of their asthma clinic visit, and completed a battery of questionnaires (Asthma Control Questionnaire, ACQ; Asthma Quality of Life Questionnaire, AQLQ; Asthma Self-Efficacy Scale, ASES). General Linear Model's assessed associations between SES (measured using educational level: $\mathrm{M}=12.9 \mathrm{yrs}$; range $2-35 \mathrm{yrs}$ ) and each morbidity measure, controlling for age, sex and asthma severity. Results indicated that lower SES was significantly associated with worse asthma control $(\mathrm{F}=11.63$, $\mathrm{p}<.001)$, greater health service use (hospitalizations) $(\mathrm{F}=5.96, \mathrm{p}<.05)$, and worse asthma self-efficacy $(\mathrm{F}=12.04, \mathrm{p}<.01)$, independent of covariates. SES was not related to worse pulmonary function or quality of life. Results suggest that SES is associated with several indices of worse asthma morbidity in adult asthmatics. Results are consistent with previous studies linking lower SES to worse asthma in children. Future studies should examine the mechanisms by which low SES adversely impacts asthma in adults.

Financial support: Grant and salary support was provided from the Fonds de la recherche en santé du Québec (KL)

\section{9}

\section{QUALITY OF LIFE IN A POPULATION-BASED SURVEY OF CANADIAN ASTHMA SUFFERERS}

Mariolaine M Limbos PHD $^{1}$, David P Joyce MD², Andrew Mclvor MD $^{3}$

${ }^{1}$ Department of Psychology, Laurentian University; ${ }^{2}$ Northern Ontario School of Medicine, Sudbury; ${ }^{3}$ McMaster University, Hamilton, Ontario

RATIONALE: Population-based surveys of asthma in Canada have demonstrated discrepancies between patients' knowledge, use of medications, and perceptions of asthma control compared to published guidelines for adequate management. The purpose of this study was to evaluate the impact of asthma control on quality of life (QOL).

METHODS: Telephone interviews were conducted on 829 adults with self-reported, doctor-diagnosed asthma. Questionnaire items included perception of asthma control, actual control based on symptom reports (compared to asthma care guidelines), and patterns of use of medications. Four items assessed impact of asthma on QOL. A second survey conducted several years later was used to assess changes in asthma control over time. RESULTS: A large proportion of patients reported that in the last 4 weeks they were "moderately" to "extremely" limited in their functioning in a number of domains of QOL. Twenty percent reported moderate to extreme limitations in physical activities (3\% extreme). Difficulty in performing activities of daily living both inside and outside the house was reported by $19 \%$ of respondents ( $3 \%$ extreme). Asthma interfered substantially with normal social activities in $13 \%$ of respondents (2\% extreme). In addition, $14 \%$ of patients reported that their asthma caused emotional problems, such as feeling anxious, depressed or irritable (1\% extreme). Patients with poor asthma control had higher mean scores on a quality of life index $(8 / 20)$ than those with adequate asthma control $(2 / 20 ; \mathrm{p}<0.05)$. There was no significant change in the proportion of patients with poor asthma control or limitations in activities between the initial and the follow up survey.

CONCLUSIONS: A substantial proportion of individuals in the community have impairments in quality of life and emotional problems related to their asthma. These impairments are strongly related to poor asthma control. Continued efforts at improving adherence to guidelines for treatment and symptom control are necessary to improve quality of life.

\section{0}

SEX DIFFERENCES IN THE RELATIONSHIP BETWEEN BODY FAT DISTRIBUTION AND ASTHMA CONTROL

M Piccioni, KL Lavoie, A Rizk, A Wright, SL Bacon

Montreal Behavioural Medicine Centre, Hôpital du Sacré-Coeur de Montreal; Department of Exercise Science, Concordia University, Montreal, Quebec

RATIONALE: Previous research, has suggested that sex plays an important role in asthma control, with women having worse control than men. As well, obesity has been shown to influence asthma control, particularly in women. However, little is known about the impact of sex and body fat distribution on asthma control. The purpose of the current study is to assess sex differences in the effects of central adiposity and total body fat on asthma control.

METHODS: 51 patients with physician diagnosed asthma, $\mathrm{M} \pm \mathrm{SD}$ age $=46 \pm 13 \mathrm{yrs}, 42 \%$ male, completed the asthma control questionnaire (ACQ) and provided demographic information, including height, weight, and waist circumference (WC). Two general linear models were conducted to assess the relationship between adiposity and asthma control. Separate models were run for the main and interaction effects of body mass index (BMI) and sex on ACQ total, and WC and sex on ACQ, with age as a covariate.

RESULTS: There was a main effect of sex $(F=3.53, p=.067)$ and an interaction effect of sex and BMI ( $\mathrm{F}=3.47, \mathrm{p}=.069)$ on ACQ total. In addition, there was a main effect of sex $(\mathrm{F}=3.75, \mathrm{p}=.059)$ and an interaction of sex 
and WC $(\mathrm{F}=3.86, \mathrm{p}=.055)$ on ACQ scores. The main effect of sex revealed that men exhibited worse asthma control than women. The sex $\times$ WC interaction suggested that increasing WC was associated with worse control in men, with no effect in women. In contrast, the sex $\times$ BMI interaction suggested that increasing BMI was associated with better control in women, with no effect in men.

CONCLUSION: Further research is needed in larger samples to establish mechanisms by which central adiposity and total body fat influences asthma control and the variation that exists between sexes.

Financial Support: FRSQ

\section{1}

\section{EFFECTS OF INHALED CORTICOSTEROIDS ON WEIGHT GAIN AMONG PATIENTS WITH ASTHMA}

Amanda Rizk, V Pepin, KL Lavoie, M Joseph, A Wright, H Favreau,

\section{SL Bacon}

Montreal Behavioural Medicine Centre, Hôpital du Sacré-Coeur de Montréal; Department of Exercise Science; Concordia University, Montreal, Quebec

Inhaled corticosteroids (ICS) play an important role in the management of asthma symptoms by reducing airway inflammation, one of the hallmark physiological characteristics of this respiratory illness. Several studies have shown that asthma is related to body weight and weight gain and asthma exacerbation, and that this relationship might be sex specific. Corticosteroids have been associated with weight gain. However, little is known about the effect of ICS use on weight gain among patients with asthma. We hypothesized that the use of ICS will trigger weight gain among patients with asthma, and specifically, women with asthma will have greater weight gain compared to men. In total 169 adult patients with asthma provided details of their medical history (including ICS use) and demographic information (including weight and height). All participants provided the same information at one year. General linear models revealed a main effect of ICS dose $(\mathrm{F}=5.23, \mathrm{P}=.024)$, sex $(\mathrm{F}=3.87, \mathrm{P}=.051)$, as well as the interaction between ICS dose and sex $(\mathrm{F}=4.69, \mathrm{P}=.032)$ on BMI change, controlling for age, smoking status, level of education and baseline BMI. Results indicate that a greater ICS dose was associated with increased weight gain at 1 year and women had greater weight gain than men. Further analysis of the interaction indicated that women had greater weight gain with increased ICS dose; whilst men had decreased weight gain with increased ICS dose. This finding could possibly be due to hormonal sex differences interacting with ICS usage, yet more studies are needed to examine this relationship.

\section{2}

\section{DOES ASTHMA SELF-EFFICACY PREDICT ADHERENCE TO DAILY ASTHMA CONTROLLER MEDICATION?}

DA Samek, KL Lavoie, MF Joseph, B Ditto, SL Bacon Montreal Behavioral Medicine Center, Hôpital du Sacré-Coeur; Psychology, McGill University; Exercise Science, Concordia University; Psychologie, Université de Québec à Montréal (UQAM); Montreal, Quebec

A major obstacle in asthma treatment is poor patient adherence to daily controller medication, inhaled corticosteroids (ICS). Patients with uncontrolled asthma have more exacerbations and use more health care resources. Previous research has shown that asthma self-efficacy, or the belief in one's ability to manage or control asthma symptoms, is related to asthma control independent of age, sex, and asthma severity. However, little is known about the relationship between self-efficacy and adherence to controller medication. It was hypothesized that low asthma self-efficacy would be associated with worse adherence to ICS treatment. 224 patients with documented asthma ( $41 \%$ men; $M$ age 48 years) underwent a sociodemographic, medical, and psychiatric (PRIME-MD) interview, completed a battery of questionnaires including the Asthma Self-Efficacy Scale (ASES), and underwent pulmonary function testing. Self-reported ICS adherence was defined as either "generally, I take my controller medications as prescribed" or "generally, I do not take my controller medications as prescribed." $75 \%$ of the sample $(n=168)$ reported that they take their medication "as prescribed." When ASES was split into quartiles, logistic regression analyses revealed that ASES tended to be related to selfreported adherence $(\mathrm{OR}[95 \% \mathrm{CI}]=1.29, \mathrm{p}=.097)$, controlling for age, sex, number of asthma medications currently taking, and asthma severity. Thus, patients with lower levels of self-efficacy tended to adhere less to ICS treatment. A limitation of the current study was our subjective measure of adherence. Self-report data may have accounted for the unusually high level (i.e. overestimation) of adherence in this sample. Future research should employ objective measurement of ICS adherence to better examine the potential association between ASES and adherence.

Financial support: Grant support was provided from the Fonds de la recherche en santé du Québec (FRSQ) and IRSST

\section{3}

\section{EFFECT OF SMOKING ON ASTHMA QUALITY OF LIFE} Alicia Wright BSc, Kim L Lavoie PhD, Maryann Joseph BA, Amanda Rizk BSc, Simon L Bacon PhD

Montreal Behavioural Medicine Centre, Hôpital du Sacré-Cœur de Montréal; Department of Exercise Science, Concordia University, Montreal, Quebec

INTRODUCTION: Asthma is an increasingly prevalent respiratory condition, currently affecting an estimated 2.5 million Canadians. Accumulated research has demonstrated that smoking has a negative impact upon respiratory health. Smoking is also one of the known triggers of asthma symptoms. However, few studies have explicitly examined the effects of smoking on asthma quality of life (AQL). It is hypothesized that people who smoke will have worse AQL.

METHODS: In total, 650 adult asthmatic outpatients at l'Hôpital du Sacré-Coeur de Montréal underwent a brief socio-demographic and medical history interview. Patients also completed the AQL questionnaire (AQLQ) which provides a total score as well as four subscale scores: limitations, symptoms, emotion, and environment.

RESULTS: General linear model analyses revealed that smoking status was significantly associated with total $\mathrm{AQL}(\mathrm{F}=4.02, \mathrm{p}=.018)$ as well as the emotion ( $\mathrm{F}=3.63$, p.027) and symptoms $(\mathrm{F}=6.17, \mathrm{p}=.002)$ subscales, independent of age and sex. Post-hoc analyses revealed that current smokers had significantly lower total AQLQ compared to never smokers (5.21 \pm 0.07 vs. $4.74 \pm 0.16)$, with neither group different from previous smokers $(5.07 \pm 0.07)$. However, when asthma control was included in the model there was no longer a significant effect of smoking on AQL and measure of AQLQ (all p's>.05).

CONCLUSION: Results suggest that smoking influences AQL when controlling for age and sex. However, the relationship between smoking and AQL seems to be mediated by asthma control. Further studies are needed to explore the mechanisms and impact of these relationships. For example, further examination of the relationship using packages/year and an assessment of the longitudinal relationship is warranted.

Financial Support: Fonds de la recherche en santé du Québec and Canadian Institute of Health Research

\section{4}

\section{IMPROVED SURVIVAL WITH TIOTROPIUM COMPARED TO LONG ACTING BETA-2-AGONISTS FOR OLDER PATIENTS WITH CHRONIC OBSTRUCTIVE PULMONARY DISEASE (COPD)}

Andrea Gershon MD MSc ${ }^{1,2,3}$, Li Wang $\mathrm{MD}^{4}$, Teresa To $\mathrm{PhD}^{1,2,3}$, Jin Luo MD MSc ${ }^{1}$, Ross Upshur MD MSc MA ${ }^{1,3,4}$

${ }^{1}$ Institute of Clinical Evaluative Sciences; ${ }^{2}$ The Hospital For Sick Children; ${ }^{3}$ University of Toronto; ${ }^{4}$ Sunnybrook Health Sciences Centre, Toronto, Ontario

RATIONALE: COPD is the fourth leading cause of chronic morbidity and mortality in North America. Tiotropium has been shown to reduce exacerbations, hospitalizations, symptoms, and improve health-related quality of life in patients with COPD. Its effects in relation to long-acting beta-agonists and on mortality, however, remain unknown.

METHODS: To examine the relation between tiotropium and long-acting beta-agonist use on all-cause mortality in older patients with COPD, a longitudinal, population-based cohort study was conducted. Individuals 65 years and older discharged from hospital with a diagnosis of COPD 
between January 1, 2003 and March 31, 2006 in Ontario, Canada were included. Survival analysis was used to examine mortality at 180 days. RESULTS: Of 7218 eligible patients, 1046 (14.5\%) died in the follow-up period. The hazard of receiving a prescription for tiotropium compared to a long-acting beta-agonist on all-cause mortality, controlling for a number of potential confounders such as age, sex, other medications, and various markers of disease severity, was 0.80 (95\% confidence interval 0.70 to 0.93 ). This association was maintained when only patients on inhaled corticosteroids were considered.

CONCLUSION: In older patients recently discharged from hospital for COPD, tiotropium was associated with reduced mortality compared to long-acting beta-agonists. This result suggests that tiotropium might also be associated with decreased mortality compared to no treatment at all. Randomized placebo-control trials are needed to confirm these findings.

\section{5}

\section{IDENTIFYING PATIENTS DIAGNOSED WITH CHRONIC OBSTRUCTIVE PULMONARY DISEASE (COPD) USING HEALTH ADMINISTRATIVE DATA}

Andrea Gershon MD MSc FRCPC ${ }^{1,2,3}$, Chengning Wang MD MSc ${ }^{1}$, Jovanka Vasilevska-Ristovska MD ${ }^{1}$, Juan Guan $\mathrm{MSc}^{3}$, Lisa Cicutto PhD ACNP CAE ${ }^{2}$, Teresa To PhD ${ }^{1,2,3}$

${ }^{1}$ The Hospital For Sick Children; ${ }^{2}$ University of Toronto; ${ }^{3}$ Institute for Clinical Evaluative Sciences, Toronto, Ontario

RATIONALE: A case validation study was conducted to determine if individuals with COPD could be accurately identified in health administrative databases for on-going surveillance.

METHODS: Medical records of individuals aged 19 to 80 years with $(n=113)$ or without COPD $(n=405)$ were randomly selected from 13 primary care practices in Ontario, Canada. Clinical information was abstracted and interpreted by a panel of pulmonologists to establish a gold standard diagnosis. This diagnosis was then linked to each individual's health administrative database records and compared with various claim algorithms. The test characteristics of the algorithms were calculated and compared.

RESULTS:

Test Characteristics of Algorithms for COPD

\begin{tabular}{|c|c|c|c|c|c|}
\hline $\begin{array}{l}\text { Algorithm (Number and type of } \\
\text { claims) }\end{array}$ & $\begin{array}{l}\text { Time period } \\
\text { (years) }\end{array}$ & $\begin{array}{l}\mathrm{Sn} \\
(\%)\end{array}$ & $\begin{array}{l}\mathrm{Sp} \\
(\%)\end{array}$ & $\begin{array}{l}\text { PPV } \\
(\%)\end{array}$ & $\begin{array}{r}\text { NPV } \\
(\%)\end{array}$ \\
\hline $\begin{array}{l}\geq 1 \text { outpatient/emergency claim or } \\
\geq 1 \text { hospitalization }\end{array}$ & unspecified & 85.0 & 84.2 & 60.0 & 95.3 \\
\hline \multirow{2}{*}{$\begin{array}{l}\geq 2 \text { outpatient/emergency claims or } \\
\geq 1 \text { hospitalization }\end{array}$} & 2 & 66.4 & 93.8 & 75.0 & 90.9 \\
\hline & 3 & 67.3 & 93.6 & 74.5 & 91.1 \\
\hline \multirow{2}{*}{$\begin{array}{l}\geq 3 \text { outpatient/emergency claims or } \\
\geq 1 \text { hospitalization }\end{array}$} & 2 & 59.3 & 96.1 & 80.7 & 89.4 \\
\hline & 3 & 60.2 & 96.1 & 81.0 & 89.6 \\
\hline
\end{tabular}

NPV Negative predictive value; PPV Positive predictive value; Sn Sensitivity; Sp Specificity

CONCLUSIONS: Our results confirm that a health service use based algorithm can accurately identify individuals with COPD for on-going surveillance. An algorithm of at least 1 health service claim (outpatient, emergency visit or hospitalization) attributable to COPD appears to give the best combination of sensitivity $(85.0 \%)$ and specificity $(84.2 \%)$.

Funded by: Ontario Ministry of Health and Long-Term Care

\section{6}

COPD CASE FINDING USING SYMPTOM-BASED TARGETED VS ROUTINE SPIROMETRY IN PRIMARY CARE PATIENTS AT HIGH RISK FOR COPD

$\underline{\mathrm{R} \text { Hodder } M D^{1}}$, R Goldstein $\mathrm{MD}^{2}, \mathrm{M}$ Stanbrook $\mathrm{MD}^{2}$, G Guyatt $\mathrm{MD}^{3}$, W Tan $\mathrm{MD}^{4}$, M Blouin, P Bragaglia MD, I Tamari MD, L Calcutt

${ }^{1}$ University of Ottawa, Ottawa; ${ }^{2}$ University of Toronto, Toronto; ${ }^{3}$ McMaster University, Hamilton, Ontario; ${ }^{4}$ University of British Columbia, Vancouver, British Columbia

RATIONAL AND METHODS: We compared diagnostic sensitivities of routine vs targeted post-bronchodilator spirometry using a five element, symptom-based, questionnaire reflecting the MRC domains of cough, phlegm, dyspnea, wheeze and exacerbations for case finding of GOLD Stage II COPD (GSII) as defined by $\mathrm{FEV}_{1}<80 \%$ plus EV1/FVC $<0.70$. Only patients 40 years with 20 pack years (PY) smoking are reported.

RESULTS: Of 536 subjects; mean age 61 yr (54\% male); mean 34 PY, $21.6 \%$ had GSII. Of the $35 \%$ who were asymptomatic, $18 \%$ had GSII. The percentages of subjects symptomatic in 1, 2, 3, 4, or 5 of the MRC domains and having GSII were: $23 \% / 16 \%, 17 \% / 25 \%, 6 \% / 28 \%, 8 \% / 28 \%$, and $3 \% / 44 \%$ respectively. Of the $65 \%$ of subjects symptomatic in $1 \mathrm{MRC}$ domain, $23.9 \%$ had GSII and of the $43 \%$ symptomatic in 2 MRC domains, $27.8 \%$ had GSII. Results were not affected by PY. Of those with GSII airflow obstruction, only $31 \%$ had a previous diagnosis of COPD (mean FEV1 58.1\%, FEV $1 /$ FVC 0.52). The $69 \%$ who were undiagnosed had slightly milder airflow obstruction (mean $\mathrm{FEV}_{1} 70.5 \%, \mathrm{FEV}_{1} / \mathrm{FVC} 0.64$ ). A diagnosis of COPD had been made in $5.2 \%$ of subjects who did not have significant airflow obstruction (mean $\mathrm{FEV}_{1} 81 \%, \mathrm{FEV}_{1} / \mathrm{FVC} 0.73$ ).

CONCLUSIONS: In this study population, case finding by routine spirometry would have led to a prevalence of GSII COPD of $21.6 \%$, of whom only a minority would have been previously diagnosed. Spirometry targeted only to subjects with one or more COPD-compatible symptoms, as recommended by GOLD, would have led to only a slightly higher prevalence of GSII COPD. Whether, targeted spirometry in symptomatic subjects with $<20 \mathrm{PY}$ would lead to a higher prevalence of undiagnosed COPD with milder airflow obstruction (e.g. GOLD Stage I) is currently being explored.

Funded By: MOHLTC, Ontario

\section{7}

\section{FEATURES OF UNDIAGNOSED AND MISDIAGNOSED COPD IN PRIMARY CARE}

Matthew B Stanbrook MD PhD ${ }^{1}$, M Blouin ${ }^{2}$, GH Guyatt MD ${ }^{3}$, R Hodder $\mathrm{MD}^{4}$, WC Tan $\mathrm{MD}^{5}$, I Tamari, P Bragaglia, RS Goldstein $\mathrm{MB} \mathrm{ChB}^{1,2}$

${ }^{1}$ University of Toronto; ${ }^{2}$ West Park Healthcare Centre, Toronto;

${ }^{3}$ McMaster University, Hamilton; ${ }^{4}$ University of Ottawa, Ottawa, Ontario; ${ }^{5}$ University of British Columbia, Vancouver, British Columbia

RATIONALE: COPD is often not recognized accurately in practice. We sought to identify clinical features of undiagnosed and misdiagnosed COPD in primary care.

METHODS: Adults aged 40 or older who had smoked at least 20 packyears were enrolled during a primary care visit for any reason and underwent pre- and post-bronchodilator spirometry. Patients found to have incompletely reversible obstruction $\left(\mathrm{FEV}_{1} / \mathrm{FVC}<0.7\right.$ and $\mathrm{FEV}_{1}<80 \%$ predicted) were designated spirometry positive and matched by site, sex, and age to patients without obstruction; designated spirometry negative. Prior diagnosis of COPD and other clinical data were identified via chart review. Patients were classified as correctly diagnosed COPD (spirometry positive, chart positive), undiagnosed COPD (spirometry positive, chart negative), misdiagnosed COPD (spirometry negative, chart positive), and non-COPD (spirometry negative, chart negative).

RESULTS: Among 564 participants, 116 (20\%) had spirometric evidence of COPD. Compared to correctly diagnosed COPD, undiagnosed COPD patients were younger ( 62.5 vs. 65.5$)$, more likely to be female ( $67 \%$ vs. $50 \%)$ and ex-smokers ( $84 \%$ vs. $36 \%)$, had less severe obstruction $\left(\mathrm{FEV}_{1}\right.$ $72 \%$ vs. $57 \%$ predicted, $\mathrm{P}<0.001$ ), and seldom used respiratory medications ( $17 \%$ vs. $93 \%$ ), yet had greater smoking exposure (44 vs. 33 packyears). Misdiagnosed COPD patients were similar to correctly diagnosed COPD in age, gender, and smoking exposure, yet had less severe obstruction $\left(\mathrm{FEV}_{1} 82 \%\right.$ vs. $\left.57 \%, \mathrm{P}<0.001\right)$ and were less likely to use inhaled anticholinergics ( $25 \%$ vs. $100 \%, \mathrm{P}=0.004)$

CONCLUSIONS: Compared to correctly diagnosed COPD, undiagnosed COPD had less evidence of disease activity, while misdiagnosed COPD had less use of anticholinergic medications.

Funded By: Ontario Ministry of Health and Long-Term Care 
18

FEASIBILITY OF CONDUCTING THE MULTISITE CANADIAN OBSTRUCTIVE LUNG DISEASE (COLD) STUDY USING THE STANDARDIZED BURDEN OF OBSTRUCTIVE LUNG DISEASE (BOLD) PROTOCOL

Wan C Tan ${ }^{1}$, Don Sin ${ }^{1}$, M Fitzgerald ${ }^{2}$, Jean Bourbeau ${ }^{3}$,

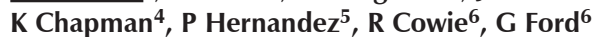

${ }^{1}$ UBC iCapture Centre; ${ }^{2}$ Vancouver Gen Hospital, Vancouver, British Columbia; ${ }^{3}$ The Montreal Chest Institute - McGill University Health Centre, Montreal, Quebec; ${ }^{4}$ Asthma and Airway Centre, Toronto Western Hospital, Toronto, Ontario; ${ }^{5}$ Halifax Infirmary, Halifax, Nova Scotia; ${ }^{6}$ Department of Medicine, University of Calgary, Calgary, Alberta

RATIONALE: There is no measured prevalence of COPD in Canada. An accurate database of COPD in Canada and a tool to project economic and social burden would help inform governments and health planners. Vancouver, BC participated in the Burden of Obstructive Lung Disease (BOLD) study, an international initiative to collect population-based prevalence data throughout the world using common and standardized methodologies (protocol, equipment, staff training, data collection, centralized quality control of spirometry performance and data management; and a common data-analysis) (Lancet 07).

AIM: Extension of the initial BOLD study in Vancouver to several centers within Canada to provide nationally important epidemiological data on COPD and lung health.

METHOD: The BOLD protocol for data collection is replicated at each site. This consisted of an interviewer-administered questionnaire on respiratory symptoms, potential risk factors, health-related quality of life, and spirometry before and after bronchodilator administration. The sampling method for all sites is by random digit dialing (RDD) to translate a sampling frame of households in each study site to a simple random sample of adults aged 40 years and older. The quality assurance for spirometry, questionnaire data uploading and data cleansing for the Vancouver site was conducted by Portland, Oregon, USA and replicated by Vancouver, BC for the other 4 sites.

RESULTS: The study is ongoing. To date, two (Vancouver, Montreal) of the 5 participating sites (Vancouver, Montreal, Toronto, Halifax, Calgary) have completed data collection. For recruits 40 years and older $(40+)$, complete questionnaire data and spirometry with reversibility were collected from 878 in Vancouver, and 558 in Montreal. Short telephone questionnaire (minimal data) for 18 years and older (18-39) were collected from 648 subjects in Vancouver and 798 subjects in Montreal. In the ongoing centers (Toronto, Halifax, Calgary), to date, minimal data had been collected from 768 subjects in 18-39 group and 674 in $40+$ group (Toronto); the respective numbers to date for Halifax being 67 and 45 . Calgary has just started.

CONCLUSION: The use of a comprehensive standardized study protocol is an accurate and effective way to construct a national database and cohort for further longitudinal studies.

Financial Support: AstraZeneca, Boehringer Ingleheim, GlaxoSmithKline, Pfizer

\section{9}

\section{THE IMPACT OF QUALITY ASSURANCE ON} PARTICIPATION/RESPONSE RATES AND SPIROMETRY ACCEPTANCE RATE IN THE CANADIAN OBSTRUCTIVE LUNG DISEASE (COLD) - DATA FROM THE MONTREAL SITE

Wan C Tan ${ }^{1}$, Jeong E Min ${ }^{1}$, Palmina Mancino², Jean Bourbeau ${ }^{2}$ ${ }^{1}$ UBC iCapture Centre, St Paul's Hospital, Vancouver, British Columbia; ${ }^{2}$ The Montreal Chest Institute McGill University Health Centre, Montreal, Quebec

RATIONALE: The COLD (Canadian Obstructive Lung Disease) initiative is a population-based lung health study conducted in 5 cities in Canada. HYPOTHESIS: Quality assurance of the conduct of a multi-site initiative can improve the completion rate and the accuracy of the collected data. METHODS: The COLD initiative is standardized by using the BOLD protocol for all sites.
The BOLD protocol includes standardized lung health questionnaires, standardized performance of spirometry and standardized conduct of the study. The conduct of the study includes continuous surveillance and quality assurance of the participation rate; monitoring the accuracy of questionnaires upload; and scoring of spirometry tracings according to ATS criteria, with instant site feedback and reminder of unacceptable criteria. RESULTS: The results for the Montreal site are reported. The main impact of COLD quality assurance is an increase in participation rate from $44 \%$ to a final $70 \%$. The correctable errors in questionnaire contents or transcribing occurred in $38 \%$ of all cases and include skip sequence errors in $31 \%$, duplicate uploading $7 \%$, incomplete uploading $5 \%$, age/gender errors $9 \%$, with more than 1 error present in any one questionnaire.

The main errors in spirometry tracings include non reproducible (difference between two best values $>200 \mathrm{ml}$ ) $\mathrm{FEV}_{1}$ or FVC $3 \%$, all forced expiratory time less than 6 seconds $3 \%$, less than 3 acceptable curves $2 \%$, postbronchodilator FVC less than prebronchodilator value by $200 \mathrm{ml}$ $16 \%$. The final proportion of tracings acceptable for analysis of the primary outcome of interest (COPD prevalence) is: $97 \%$ of postbronchodilator $\mathrm{FEV}_{1}$ and $\mathrm{FVC}$.

CONCLUSION: Quality assurance improves the participation rate, the acceptability rate of spirometry tracings and questionnaire data accuracy in a multisite lung health study.

Financial Support: AstraZeneca, Boehringer Ingleheim, GlaxoSmithKline, Pfizer

\section{0}

\section{UNDERDIAGNOSIS OF COPD AND ASSOCIATED CARDIOVASCULAR COMORBIDITY IN THE POPULATION - RESULTS FROM THE VANCOUVER AND KENTUCKY POPULATION BOLD STUDY}

Wan C Tan $\mathrm{MD}^{1}$, H Muellerova $\mathrm{PhD}^{2}$, S Buist $\mathrm{MD}^{3}$, B Vollmer $\mathrm{PhD}^{4}$, D Mannino MD

${ }^{1}$ UBC iCapture Centre, Vancouver, British Columbia; ${ }^{2}$ GlaxoSmithKline R\&D, United Kingdom; ${ }^{3}$ Oregon Health and Sciences University; ${ }^{4}$ Kaiser Permanente Centre for Health Research, Portland, Oregon; ${ }^{5}$ University of Kentucky, Lexington, Kentucky, USA

RATIONALE: The burden of COPD is greater than recognized as much COPD is underdiagnosed, but there is little information on phenotypic differences between undiagnosed and diagnosed COPD.

AIM: To estimate the proportion of patients with spirometry-defined COPD $\left(\mathrm{FEV}_{1} / \mathrm{FVC}<0.7\right)$ that have different stages of disease severity, cardiovascular comorbidity and history of COPD exacerbations, and to explore these phenotypes in three populations: physician diagnosed COPD, physician undiagnosed COPD and treated COPD (physician diagnosed or undiagnosed).

METHODS: The study population consists of two combined cohorts, created as a part of the Burden of Lung Disease (BOLD) study in Lexington (KY,US) and Vancouver (BC, Canada). Both cohorts are representative of the local general population and were selected using an identical methodology, random digital dialing. The population is limited to adults aged 40 years and older who completed a questionnaire and pre- and postbronchodilator spirometry. All analyses are adjusted for age.

RESULTS: The total analyzable population is 508 for Kentucky and 827 for Vancouver. The population prevalence was $19.6 \%$ for Kentucky and 19.3\% for Vancouver. A combined 247 subjects had COPD with GOLD 1 or higher severity. Of all COPD subjects, $26 \%$ had a physician diagnosis; $74 \%$ were undiagnosed and $30 \%$ had received respiratory treatment. Those with a physician diagnosis or are receiving treatments are more likely to have more severe disease and have exacerbation or heart disease compared with undiagnosed COPD $(\mathrm{P}<.005)$ respectively. Cardiovascular morbidity was increased in COPD subjects compared with non COPD subjects $(\mathrm{P}=.035)$, but irrespective of COPD severity $(\mathrm{P}=.74)$.

CONCLUSION: The burden of COPD in the population is markedly underestimated, and heart disease is closely associated with COPD.

Financial Support: AstraZeneca, Boehringer Inglehiem, GlaxoSmithKline, Pfizer 


\section{CHRONIC OBSTRUCTIVE PULMONARY DISEASE STREAM}

\section{1}

\section{ACUTE EXACERBATION OF COPD: DETERMINANTS OF LENGTH OF HOSPITAL STAY AND READMISSION}

Alyson W Wong ${ }^{1}$, Jane Burns ${ }^{2}$, Wan Gan ${ }^{2,3}$, D Sin ${ }^{2}$, S van Eeden ${ }^{2}$ ${ }^{1}$ UBC Faculty of Cell Biology and Genetics; ${ }^{2}$ St. Paul's Hospital; 3 iCAPTURE Centre, Biostatistics, Vancouver, British Columbia RATIONALE: Chronic Obstructive Pulmonary Disease (COPD) is the 4th leading cause of death in Canada with the direct cost in 1998 estimated at $\$ 1.67$ billion. Acute COPD exacerbation (AECOPD) is a defining complication in COPD, a major predictor for morbidity and mortality and the most common reason for hospitalization in British Columbia. Numerous factors have been identified that predict AECOPD and influence eventual length of stay (LOS). Utilizing Canadian Thoracic Society (CTS) COPD Guidelines as a standard for optimal treatment, we hypothesized that patients managed in a downtown hospital (St. Paul's Hospital $[\mathrm{SPH}])$ have more frequent and severe COPD exacerbations resulting in increased length of hospital stay.

METHODS: Chart reviews were performed on patients admitted to SPH with a diagnosis of COPD exacerbation between October 2006 and March 2007 (inclusive). Exacerbations were classified according to Anthonisen criteria to determine severity of exacerbation upon admission and scored using the GOLD criteria. Pertinent clinical and laboratory information were extracted from patient charts. Statistical analysis was performed using SPSS; dependent variables were LOS and readmission. Patients were matched for severity of disease (GOLD criteria), age, sex and smoking history.

RESULTS: Of 109 admissions to SPH, 61\% were single admissions and $39 \%$ were readmissions. Range of readmissions was 2 to 9, with an average of 3.3 readmissions. Average age of patients with a single admission ( 65.9 years) was older than readmitted patients ( 58.7 years). Single admission patients tended to stay longer in hospital ( 8.5 days) compared to readmitted patients ( 7 days). Readmitted patients had more severe COPD based on GOLD classification criteria. The strongest indicator for readmission was GOLD status, comorbidities and single marital status.

CONCLUSION: Findings confirm previous studies indicating severity of COPD and disease comorbidities determines readmission of AECOPD but socio-economic and social factors also predict likelihood of readmitting.

\section{2}

\section{THE MANAGEMENT OF COPD IN A SPECIALIZED CLINIC:} BETTER ADHERENCE TO CTS GUIDELINES?

\section{Samuel Wasswa-Kintu ${ }^{1}$, 」ane Burns ${ }^{2}{ }^{\text {, D Sin }}{ }^{2}$, S van Eeden ${ }^{2}$} ${ }^{1}$ UBC Faculty of Pharmaceutical Sciences; ${ }^{2}$ St. Paul's Hospital, Vancouver, British Columbia

RATIONALE: Chronic Obstructive Pulmonary Disease (COPD) is the fourth leading cause of death of Canadians as reported by Statistics Canada. The Canadian Thoracic Society (CTS) published a National Report Card in 2005 citing significant deficiencies in COPD management, according to CTS Guidelines. In February 2005, a multi-disciplinary COPD clinic was established at St. Paul's Hospital as part of the Pacific Lung Health Centre (PLHC). The goal was to establish a comprehensive chronic disease management program for COPD patients. We hypothesized that patients managed in a specialized COPD clinic would receive care more consistent with the CTS Guidelines than COPD patients managed by general Respirologists.

METHODS: 140 COPD clinic patients and 250 randomly selected COPD patients from the general Respirology clinic setting seen between February 1, 2005 and February 1, 2007 were compared. The most recent COPD visit and spirometry data were used in comparison of demographic history, smoking status and disease severity (GOLD Classification and Dyspnea score) between the two groups. All COPD visit records were then examined for specific recommendations including smoking cessation, exercise, further tests, vaccinations, nutritional counseling, COPD education and pulmonary rehabilitation.
RESULTS: Both groups were comparable in age, sex and COPD severity based on the GOLD Classification. Patients treated in the COPD clinic were significantly more likely to receive the following recommendations: Flu/pneumovax vaccination $(\mathrm{p}<0.001)$, nutritional counseling $(\mathrm{p}<0.001)$, COPD education $(\mathrm{p}<0.001)$ and pulmonary rehabilitation $(\mathrm{p}<0.001)$. Subjects with severe COPD were more often evaluated for oxygen requirements (walking oximetry, $\mathrm{p}=0.020$ ), and lung imaging for LVRS (chest $\mathrm{x}$-rays, $\mathrm{p}<0.001$ and CT scans, $\mathrm{p}=0.001$ ).

CONCLUSION: The management of COPD in a dedicated clinic is more consistent with the CTS Guidelines for Management of COPD compared to treatment outside a specialized clinic, especially for nonpharmacological interventions.

Financial Support: Financed in part by an unrestricted grant from GlaxoSmithKline PRIISME COPD project

\section{3}

\section{THE COST OF MODERATE AND SEVERE COPD} EXACERBATIONS TO THE CANADIAN HEALTHCARE SYSTEM IM FitzGerald MB FRCPC ${ }^{1}$, L Kuramoto MSc $^{1}$, SJ Seung BSc ${ }^{2}$, JM Haddon $\mathrm{MSc}^{3}$, C Bradley-Kennedy $\mathrm{MSc}^{3,4}$, N Mittmann MSc PhD ${ }^{2,4}$

${ }^{1}$ Centre for Clinical Epidemiology and Evaluation, Vancouver Coastal Health Research Institute, University of British Columbia, Vancouver, British Columbia; ${ }^{2}$ Health Outcomes and PharmacoEconomic (HOPE) Research Centre, Division of Clinical Pharmacology, Sunnybrook Research Institute, Sunnybrook Health Sciences Centre, University of Toronto, Toronto; ${ }^{3}$ Boehringer Ingelheim (Canada) Limited, Burlington; ${ }^{4}$ Department of Pharmacology, University of Toronto, Toronto, Ontario

RATIONALE: The cost of exacerbations in chronic obstructive pulmonary disease (COPD) has not been well studied. The aim of this study was to identify and quantify the (average) cost of moderate and severe exacerbations (ME and SE, respectively) from a Canadian perspective.

METHODS: Resources used during ME and SE were identified in a year long prospective, observational study (RUSIC). The units of analysis were ME and SE. Unit costs (2006 \$CAN), based on provincial, hospital and published sources, were applied to resources. The overall cost per ME and SE were calculated. The population burden of exacerbations was also calculated.

RESULTS: Among study participants ( $\mathrm{N}=609$, aged $68.6 \pm 9.4$ years, $58.3 \%$ male) there were 790 exacerbations: 639 (80.9\%) MEs and $151(19.1 \%)$ SEs. Of the 790 exacerbations, 618 (78.2\%), 245 (31.0\%) and 151 (19.1\%) included a visit to an outpatient clinic, emergency department (ED) or hospital, respectively. For ME, $85.9 \%$ and $13.1 \%$ involved visits to GPs and respirologists, respectively. The majority of pharmacologic treatment changes in the outpatient setting involved antibiotics $(63.1 \%)$ and corticosteroids (34.7\%). The overall mean costs for outpatient and ED services for MEs were $\$ 127(\mathrm{~N}=574)$ and $\$ 515(\mathrm{~N}=105)$, respectively. The average overall cost of a ME was $\$ 641$. For SEs, the average hospital stay was 10.0 days. The overall mean costs of outpatient, ED and hospitalization services for SE were $\$ 114(\mathrm{~N}=44), \$ 774(\mathrm{~N}=140)$ and $\$ 8,669(\mathrm{~N}=151)$, respectively. The average overall cost of a SE was $\$ 9,557$.

CONCLUSION: The economic burden associated with MEs and especially SEs, in Canada, is considerable and likely has a substantial impact on healthcare costs. The overall burden of exacerbations has been estimated in the range of $\$ 646$ million to $\$ 736$ million per annum.

This study was sponsored by Pfizer Canada Inc. and Boehringer-Ingelheim Canada Ltd.

\section{4}

THE DYING PATIENT WITH COPD: SYMPTOM MANAGEMENT CHALLENGES AND ETHICAL CONCERNS IN THE ICU Donna Goodridge RN PhD CHPCN(C) ${ }^{1}$, John Gjevre MD FACP ${ }^{2}$, Donna Rennie RN PhD ${ }^{1,3}$, Wendy Duggleby RN PhD AOCN(C) ${ }^{1}$ ${ }^{1}$ College of Nursing; ${ }^{2}$ College of Medicine; ${ }^{3}$ Canadian Centre for Health and Safety in Agriculture, University of Saskatchewan, Saskatoon, Saskatchewan

RATIONALE: Individuals with chronic illness are recognized to be among the highest users of ICUs at the end of life. While there is widespread 
agreement that improving the quality end of life care in the ICU is a high priority, people with advanced COPD represent a unique ICU sub-population with complex psychological, pathophysiological and care trajectory needs. This study compared ICU nurses' ratings of the quality of dying and death of patients with COPD with ratings for people who died of other causes.

METHODS: Nurses in three ICUs completed the Quality of Dying and Death (QODD) Survey, a 21 item previously validated instrument, to provide their ratings of the domains of: symptoms and personal care; preparation for death; moment of death; family; treatment preferences; and whole person concerns. Usable surveys were returned for 34 patients who died with COPD and 69 patients who died from other causes.

RESULTS: Patients who died with COPD were significantly older $(p<0.001)$ than those who died from other causes. Nurse ratings were significantly lower for patients with COPD on the following items: breathe comfortably $(p<0.001)$, kept dignity and self-respect $(p=0.03)$, received the right amount of sedation $(\mathrm{p}=0.02)$, spent time with family $(\mathrm{p}=0.03)$, and were unafraid of dying $(\mathrm{p}<0.01)$. Nurses were significantly more likely $(\mathrm{p}<0.01)$ to believe that patients dying with COPD were kept alive too long compared to those without COPD.

CONCLUSIONS: Nurse ratings of the quality of dying and death suggest the need to optimize management of dyspnea and psychosocial care for patients with COPD at the end of life in the ICU setting. The ethical concern related to keeping patients with COPD "alive for too long" warrants additional exploration, both at a clinical level and as a research topic.

Funding: The authors gratefully acknowledge funding of this project through the Canadian Respiratory Health Professionals, Canadian Lung Association

\section{5}

MULTIFACETED EDUCATIONAL INTERVENTION TO OPTIMIZE THE MANAGEMENT OF PATIENTS WITH COPD IN PRIMARY CARE PRACTICE IN QUÉBEC AND ONTARIO: CAGE STUDY

Paul Hernandez, Michel Rouleau, Rolf J Sebaldt, Anna Day, Alan Kaplan, Jean Bourbeau, Jacques Bouchard, Annie Petrie, Gary Foster, Alissa Scalera, Jennifer Haddon, Lehana Thabane RATIONALE: Chronic obstructive pulmonary disease (COPD) management in primary care remains suboptimal. The CAGE study is a prospective, cross-sectional study in Québec and Ontario that was undertaken to evaluate a multifaceted educational intervention (MEI) on the practice patterns in COPD.

METHODS: Primary care physicians each recruited up to 8 successive COPD patients in four 8-week cycles. MEI was provided in three stages: (1) passive dissemination of Canadian COPD Guidelines after cycle 1; (2) 45-minute small group advisor-led teleconferences after cycle 2; and (3) 1:1 academic detailing incorporating audit and feedback on practice patterns (peer-to-peer practice refection) after cycle 3. Discrepancies between practice and guidelines were measured after each MEI stage.

RESULTS: 167 physicians recruited 3585 consecutive COPD patients ( $57 \%$ male). Mean age was 69 years; $45 \%$ were current smokers. $38 \%$ of patients had stable COPD of moderate severity, $34 \%$ had mild disease. At baseline, $66 \%$ of patients had at least one gap between prescribed pharmacological treatment and COPD guidelines. After the three MEI stages, this percentage decreased to $58 \%(\mathrm{p}<0.05)$.

CONCLUSION: Traditional educational interventions such as passive dissemination of guidelines had limited impact in reducing the overall care gap in COPD management. Peer-to-peer practice refection seems to be the most effective educational intervention. Hypotheses derived from this study will need to be further evaluated in a controlled study.

This study was sponsored by Pfizer Canada Inc. and Boehringer-Ingelheim Canada Ltd.

\section{6}

\section{SYSTEMATIC REVIEW OF PHYSIOTHERAPY DURING ACUTE EXACERBATIONS OF CHRONIC OBSTRUCTIVE PULMONARY DISEASE (AECOPD)}

Kylie Hill $^{1,2}$, Shane Patman ${ }^{3,4}$, Dina Brooks ${ }^{1,2}$

${ }^{1}$ Respiratory Medicine, West Park Healthcare Centre; and

${ }^{2}$ Department of Physical Therapy, University of Toronto, Toronto, Ontario; ${ }^{3}$ Physiotherapy School of Health Sciences, University of Notre Dame; and ${ }^{4}$ Physiotherapy Department, Fremantle Hospital, Australia

RATIONALE: In COPD patients, acute exacerbations are important events. Systematic reviews and clinical guidelines pertaining to the treatment during AECOPD focus on medical management, with little discussion of physiotherapy. Therefore a systematic review was undertaken of the studies specifically pertaining to physiotherapy during AECOPD.

METHODS: Studies were identified by searching databases and scanning reference lists. Appropriate studies were reviewed by two independent investigators. Data were extracted using a standardized form. Where possible, a score was assigned using the PEDro scale for assessment of study quality. RESULTS: 23 studies met the study criteria. Study quality was variable with a mean PEDro score of $5 \pm 2$ (range $0-7 / 10$ points). In patients hospitalized with AECOPD, the results of the studies indicated that; (i) there is little evidence for the use of chest wall percussion or vibration, (ii) positive expiratory pressure (PEP) mask therapy is useful to facilitate airway clearance in patients with copious secretions, (iii) PEP mask or intrapulmonary percussive ventilation therapy may reduce weaning time from non-invasive ventilation and the length of hospital stay, (iv) PEP mask, Flutter and expiration with an open glottis are equally effective in clearing sputum in patients with copious secretions, (v) the forward lean position reduces dyspnea, (vi) exercise training should be initiated early, and (vii) neuromuscular electrical stimulation (NMES) increases peripheral muscle strength in patients with marked disability.

CONCLUSIONS: When treating patients with AECOPD, physiotherapists should include exercise training and consider PEP, Flutter and NMES. Financial support: Great West Life Fund

\section{7}

\section{DAILY UTILITY AND SATISFACTION WITH ROLLATORS AMONG INDIVIDUALS WITH CHRONIC OBSTRUCTIVE PULMONARY DISEASE}

$\underline{K y l i e ~ H i l l}^{1}, 2$, Roger Goldstein ${ }^{1,2,3}$, Elizabeth Gartner ${ }^{4}$, Dina Brooks ${ }^{1,2}$ ${ }^{1}$ Respiratory Medicine, West Park Healthcare Centre; Departments of ${ }^{2}$ Physical Therapy and ${ }^{3}$ Medicine, University of Toronto, ${ }^{4}$ Occupational Therapy, West Park Healthcare Centre, Toronto, Ontario

RATIONALE: Rollators are prescribed for COPD patients with marked disability to increase their functional capacity and reduce dyspnoea. The daily utility and satisfaction of individuals prescribed rollators is unknown. The aim of this study was to describe the characteristics of those individuals prescribed rollators and determine their daily utility and satisfaction with the device.

METHODS: COPD subjects who had been issued with a rollator by West Park staff within the preceding 5 year period were invited to participate in the study. Following informed consent, 6-minute walk distance (6MWD) and spirometry results were extracted from the medical notes. Subjects were interviewed using the Saint George's Respiratory Questionnaire (SGRQ), the Quebec User Evaluation of Assistive Technology and a standardized questionnaire that explored daily utility. The order of questionnaire administration was randomized.

RESULTS: 27 COPD subjects ( $\mathrm{FEV}_{1}=35 \pm 22 \%$ predicted; 10 males) completed the study. $67 \%$ were using long term oxygen therapy. Exercise capacity and health-related quality of life were poor $(6 \mathrm{MWD}=45 \pm 11 \%$ pred, total SGRQ $=58 \pm 14$ ). Although all subjects reported that using the rollator improved their quality of life and only $59 \%$ used the device everyday, $41 \%$ used the device in their home and $48 \%$ had been embarrassed using the rollator. Patients were most satisfied with the safety, durability, ease of use and effectiveness of the device and least satisfied with its weight. 
CONCLUSIONS: Most COPD patients prescribed rollators for use in the community have severe disease, poor health-related quality of life and use long term oxygen therapy. Consideration should be given to minimizing the weight of the device and any initial embarrassment.

Financial support: Ontario Respiratory Care Society, National Sanitarium Association

\section{8}

\section{SIMILAR GAINS IN FUNCTIONAL EXERCISE CAPACITY FOLLOWING A REPEAT PROGRAM OF PULMONARY REHABILITATION (PR): A REVIEW OF OUR CLINICAL COHORT}

$\underline{\text { Kylie Hill }}^{1,2}$, Vishal Bansal' ${ }^{1}$, Dina Brooks ${ }^{1,2}$, Roger Goldstein ${ }^{1,2,3}$

${ }^{1}$ Respiratory Medicine, West Park Healthcare Centre; Departments of ${ }^{2}$ Physical Therapy, and ${ }^{3}$ Medicine, University of Toronto, Toronto, Ontario

RATIONALE: Although the benefits of PR diminish over time, we know little about strategies, such as repeat programs, designed to maintain improved function. The aims of this study were to describe the; (i) uptake of a repeat PR program within 5 years of the initial program, and (ii) effects of repeat PR on functional exercise capacity.

METHODS: A comprehensive 5-year retrospective chart review was conducted of patients who completed at least 4 weeks of in-patient PR in 2001. Data were extracted pertaining to lung function and functional exercise capacity (six-min walk distance; 6MWD and self-paced endurance walk; EW).

RESULTS: In 2001, 89 patients $\left(\mathrm{FEV}_{1}=40 \pm 18 \%\right.$ predicted; 40 males) completed PR. Of these, 21 (24\%) repeated the PR program (repeaters) an average of $24 \pm 18$ months following the 2001 program. Using data collected during the 2001 program, repeaters were similar to those that did not repeat the program in lung function, baseline 6MWD and EW, and the magnitude of change in exercise capacity following PR. Compared with their baseline 6MWD in 2001, repeaters had a lower baseline 6MWD prior to commencing the repeat program $(327 \pm 114$ vs. $282 \pm 128 \mathrm{~m})$. Baseline EW were similar for the 2001 and repeat programs ( $14 \pm 9$ vs. $11 \pm 8 \mathrm{~min})$. The magnitude of change in $6 \mathrm{MWD}$ and EW achieved during the repeat program was similar to that seen following the 2001 program, being $78 \pm 84$ vs. $91 \pm 70 \mathrm{~m}$ and $21 \pm 11$ vs. $21 \pm 11 \mathrm{~min} ; \mathrm{p}>0.6$, respectively.

CONCLUSIONS: The uptake of a repeat program within 5 years of an initial program is low. Despite starting the repeat program with worse 6MWD, such programs confer similar gains in functional exercise capacity as an initial PR program.

Financial support: National Sanitarium Association, Great West Life Fund

\section{9}

\section{MODIFYING TRACK LAYOUT FROM STRAIGHT TO CIRCULAR HAS A MODEST EFFECT ON THE SIX-MINUTE WALK DISTANCE (6MWD)}

Kylie Hill ${ }^{1,2}$, Vishal Bansal ${ }^{1}$, Thomas Dolmage ${ }^{1,3}$, Lynda Woon ${ }^{1,4}$, Roger Goldstein ${ }^{1,2,3,5}$, Dina Brooks ${ }^{1,2}$

${ }^{1}$ Respiratory Medicine, West Park Healthcare Centre; ${ }^{2}$ Department of Physical Therapy, University of Toronto, ${ }^{3}$ Respiratory Diagnostic and Evaluation Services, and ${ }^{4}$ Physiotherapy Department, West Park Healthcare Centre; ${ }^{5}$ Department of Medicine, University of Toronto, Toronto, Ontario

RATIONALE: Modifying the 6-min walk test (6MWT) protocol influences its results. A previous study concluded that institutions using continuous tracks yield greater 6MWDs than those using straight tracks. However, agreement between the 6MWDs measured on different tracks could not be examined. The aims of this study were to determine; (i) the effect of modifying track layout on 6MWD, and (ii) agreement between 6MWDs measured on different tracks.

METHODS: 27 subjects with COPD ( $\mathrm{FEV}_{1}=38 \pm 14 \%$; 15 males) attended 3 testing sessions. To account for any changes resulting from familiarization, the first two sessions comprised two 6MWTs performed on either a circular or straight track. Subjects that performed the 6MWTs on a straight track during the first session performed the 6MWTs on a circular track during the second session, and vice versa. During the final session, each subject performed one 6MWT on the straight track and one 6MWT on the circular track. The order of the track layout was randomized. RESULTS: Familiarization increased the 6MWD on straight $(404 \pm 82$ to $418 \pm 79 \mathrm{~m} ; \mathrm{p}<0.05)$ and circular tracks $(406 \pm 78$ to $418 \pm 82 \mathrm{~m} ; \mathrm{p}<0.05)$. During the final testing session, the 6MWD achieved on the circular track exceeded that achieved on the straight track $(13 \pm 17 \mathrm{~m} ; \mathrm{p}<0.01)$. The limit of agreement between tracks was $33 \mathrm{~m}$. The variability in 6MWDs introduced by modifying track layout was less than that introduced by performing the test on a different day.

CONCLUSIONS: When examining changes in 6MWD in a group of COPD patients, the track layout used for the 6MWT should be standardized. However, standardizing track layout may not be important when interpreting differences in 6MWD for individual patients.

Financial support: Canadian Respiratory Health Professionals, Physiotherapy Foundation of Canada, National Sanitarium Association, Great West Life Fund

\section{0}

SYSTEMATIC REVIEW OF ARM TRAINING IN PATIENTS WITH CHRONIC OBSTRUCTIVE PULMONARY DISEASE (COPD)

$\underline{\text { Tania Janaudis-Ferreira }}^{1,2}$, Kylie Hill1,3, Roger Goldstein ${ }^{1,3,4}$, Karin Wadell ${ }^{2}$, Dina Brooks ${ }^{1,3}$

${ }^{1}$ Respiratory Medicine, West Park Healthcare Centre; ${ }^{2}$ Department of Community Medicine and Rehabilitation, Umeå University, Sweden; Departments of ${ }^{3}$ Physical Therapy, and ${ }^{4}$ Medicine, University of Toronto, Toronto, Ontario

RATIONALE: Patients with COPD often report intolerable dyspnoea when they use their arms for simple activities of daily living. To date, no study has systematically reviewed the effects of arm training program (ATP) in patients with COPD. Therefore a systematic review was undertaken of studies that have investigated the effects of such training program.

METHODS: Studies were identified by searching electronic databases (MEDLINE, CINAHL, EMBASE, Physiotherapy Evidence Database and The Cochrane Library of clinical trials) and scanning reference lists of relevant papers. Appropriate studies were reviewed by two independent investigators. RESULTS: 13 studies met the study criteria. The results of the studies indicated that; (i) ATP alone is not as effective as leg training and that the combined training should be included in pulmonary rehabilitation programs, (ii) there is strong evidence that ATP improves arm exercise capacity and decreases $\mathrm{VE}$ and $\mathrm{VO}_{2}$ cost during arm exercise, (iii) the effects of ATP on dyspnoea, arm fatigue and quality of life are contradictory, and (iv) the best type of ATP is still unknown but unsupported arm exercise seems to be the optimal modality. Furthermore, no study has investigated the medium or long term longevity of any training-related gains seen following completion of an ATP.

CONCLUSIONS: ATP should be included in pulmonary rehabilitation programs. More randomized controlled trials are needed to confirm the effects of ATP on dyspnoea, arm fatigue and quality of life, to determine the best type of arm training for patients with COPD, and to propose the mechanisms involved in the improvement of arm function after an ATP. Financial support: Swedish Heart and Lung Foundation and West Park Foundation

\section{1}

\section{PSYCHIATRIC DISORDERS AND SEX: ARE THEY RELATED TO COPD EXACERBATIONS?}

Catherine Laurin $^{1,3,5,6}$, KL Lavoie ${ }^{1,2,6}$, M Labrecque ${ }^{1,4,6}$, A Cartier ${ }^{1,4}$, SL Bacon $1,3,5,6$

${ }^{1}$ Axe de recherche en santé respiratoire, Hôpital du Sacré-Cœur de Montréal; ${ }^{2}$ Université du Québec à Montréal (UQAM); ${ }^{3}$ Concordia University; ${ }^{4}$ Université de Montréal; ${ }^{5}$ Montreal Heart Institute; ${ }^{6}$ Montreal Behavioural Medicine Centre, Montreal, Quebec RATIONAL: The course of COPD is punctuated by acute exacerbations. Patients with COPD have a high prevalence of psychiatric disorders (up to $50 \%$ ) and women are twice as likely to suffer from psychiatric disorders as men. Psychiatric disorders and psychological distress have been shown to predict COPD exacerbations. However, no studies have been conducted to evaluate the interaction of sex and psychiatric status on the risk of exacerbations. OBJECTIVE: To evaluate the interaction effect of psychiatric disorders (anxiety and mood disorders) and sex on exacerbations in 110 patients (56 women) with COPD. 
METHOD: Patients underwent a sociodemographic and medical history interview, followed by a structured psychiatric interview (ADIS-IV). All patients underwent standard spirometry. They were followed for a mean of 2 years to evaluate the occurrence of exacerbations treated at home and at the hospital. RESULTS: Controlling for confounders (e.g., age, COPD duration and severity, pack-years, recruitment site, medical comorbidity, and time between recruitment interview and last hospitalization), men were at higher risk of exacerbations ( $R R=2.21,95 \% \mathrm{CI}, 1.17-4.16)$, including those treated inhospital $(\mathrm{RR}=2.51,95 \% \mathrm{CI}, 1.12-5.62)$ and those treated at home $(\mathrm{RR}=$ $2.30,95 \% \mathrm{CI}, 1.16-4.58)$. No significant interaction effects between sex and psychiatric status were found, such that psychiatric disorders had similar negative effect on the occurrence of exacerbations in women and men.

CONCLUSION: The results of the present study suggest that men were two times more likely to suffer from exacerbations compared to women. Efforts should be made to address sex differences in the impact of psychiatric disorders on exacerbation risk in men as well as women with COPD. Financial support: Gemma Moisan Foundation, Hôpital du Sacré-Coeur de Montréal

\section{2}

\section{OPTIMIZING PRACTICE IN COPD: THE RECAP-COPD CAREMAP PROJECT}

M Lebel RN, F Paquet RN, MF Sedeno BEng MM, J Landry MD, J Bourbeau MD

Montréal Chest Institute (MCI), McGill University, Montréal, Quebec STUDY OBJECTIVES: The COPD Caremap project aims to reduce the gap between medical practice at the $\mathrm{MCI}$ and management guidelines for COPD (CTS, 2003).

METHODS: In 2006, the "Rehabilitation, Education for COPD, and Added-value to the medical Practice (RECAP)" project showed evidence of care gaps in the chronic management of COPD. As a result, the COPD Caremap was developed for patients admitted with a primary diagnosis of COPD. The project included education to the nursing staff to increase their knowledge on COPD and to implement a chronic care approach (pharmacological and non pharmacological treatments): 1) increase patients' self-management skills; 2) increase reference to pulmonary rehabilitation and smoking cessation programs; and 3) follow-up in the community. A discharge planning tool with documentation on practice care indicators was developed and adapted according to user feedback. Continuous support was offered during the implementation ( $21 / 2$ months). RESULTS: Seventy percent $(70 \%)$ of nurses received the education training. Important changes were observed in the 4 months following implementation.

\begin{tabular}{lcc} 
Indicator & $\begin{array}{c}\text { Before Caremap } \\
(\mathbf{2 0 0 3 - 2 0 0 6 , ~} \mathbf{n = 6 9 )}\end{array}$ & $\begin{array}{c}\text { After Caremap } \\
(\mathbf{2 0 0 7}, \mathbf{n = 7 2 )}\end{array}$ \\
\hline $\begin{array}{l}\text { Patients on optimal pharmacological } \\
\text { treatment }\end{array}$ & $30.6 \%$ & $72.7 \%$ \\
$\begin{array}{l}\text { Reference to Pulmonary Rehabilitation } \\
\text { Reference to follow-up in the community }\end{array}$ & $44.4 \%$ & $81.5 \%$ \\
\hline
\end{tabular}

CONCLUSIONS: The implementation of the COPD Caremap greatly improved chronic disease care, and brought our practice closer to best guidelines recommendations.

Funded by: Agence de santé et des services sociaux (ASSS) de Montréal and an unrestricted educational grant of a consortium of the pharmaceutical industry (GlaxoSmithKline, Pfizer, Boehringer-Ingelheim, and Bristol Myers Squibb)

\section{3}

\section{INFLUENCE OF PATIENT EDUCATION IN COPD (284)}

$\underline{\text { S Mangovski-Alzamora }}{ }^{1}$, M Blouin ${ }^{1}$, R Goldstein ${ }^{1,2}$, G Guyatt ${ }^{3}$, R White $^{4}$

${ }^{1}$ Respiratory Medicine at WestPark Healthcare; ${ }^{2}$ University of Toronto and Clinical Epidemiology and Biostatistics, Toronto; ${ }^{3}$ McMaster University, Hamilton, Ontario; ${ }^{4}$ Respiratory Department Frenchay Hospital, Bristol, United Kingdom RATIONAL: Despite its inclusion in pulmonary rehabilitation programs, few studies have documented the influence of education in COPD. METHODS: Subjects with COPD were randomized to control (C) or education (E) groups, stratified according to their MRC dyspnea (stage 1-2 and stages 3-4-5) scale. Study subjects received 2, one hour, education visits from a COPD educator, 1 month apart and an assessment 1 month after the second session. Controls received usual care from their physicians, with no special focus on education. The primary outcome was the "Bristol COPD Knowledge Questionnaire (BCKQ)", a 13 topic multiple-choice questionnaire ${ }^{1}$.

RESULTS: Of 96 subjects aged $66 \pm 10 \mathrm{yr}$ ( $54 \%$ male), $31 \mathrm{E}$ and $35 \mathrm{C}$ subjects completed pre and post measures. Group characteristics and BCKQ scores, were comparable at baseline. There were 51 subjects with MRC 1-2 and 15 subjects with MRC scale 3-5. The total score for the group receiving education increased significantly, both for those with MRC 1-2 (change from $26.7 \pm 7.6$ to $36.1 \pm 7.7 \mathrm{p}<0.001$ ) and those with MRC 3-5 (change from $24.1 \pm 10.7$ to $35.3 \pm 8.2 \mathrm{p}=0.007)$. There were no significant changes in the scores among those randomized to the control group MRC 1-2 (30.6 \pm 6.7 to $30.0 \pm 7.3 \mathrm{p}=0.5)$ and MRC3-5 (32.1 \pm 9.5 to $34.1 \pm 5.4, \mathrm{p}=0.39)$.

CONCLUSIONS: Two sessions given by a COPD educator were associated with an improved education score, 1 month after the second session. Improvement in knowledge is a key step towards changing behavior among COPD patients.

${ }^{1}$ White R. Bristol COPD Knowledge Questionnaire. Chronic Respiratory Disease 2006;3:123

\section{4}

\section{TALKING ABOUT COPD: EXPLORING PATIENTS' KNOWLEDGE, ATTITUDES AND COMMUNICATION NEEDS} Anne-Marie Nicol ${ }^{1}$, Lenny Matthews ${ }^{2}$, Emily Carpenter ${ }^{1}$, Michele Bowers ${ }^{3}$

${ }^{1}$ School of Environmental Health; ${ }^{2}$ Institute for Health Promotion Research, University of British Columbia; ${ }^{3}$ Centre for Excellence in Women's Health, Women's Hospital, Vancouver, British Columbia COPD is the fourth leading cause of death in Canada. However, COPD as a disease suffers from a low public profile. While it is understood that this low profile has affected the number diagnoses of COPD, less is known about how this affects the ways that people with COPD learn about it and cope with their diagnosis. This research project explored how COPD patients, describe their own condition, access information about their disease and communicate with health professionals. A series of focus groups and interviews, led by a trained counsellor, were conducted with 29 men and women with COPD to investigate these issues. Qualitative data analysis on transcribed responses was undertaken and key themes were identified across participant responses by two independent coders using N-Vivo. The results of these analyses highlight participants' struggles with learning about their disease and the consequential impacts that these struggles have on accessing support and timely health interventions. Findings from this study emphasize the need for greater public awareness of COPD as well as the importance of emotional support for patients interested in self-care. Research supported by ICEBERGS, an Interdisciplinary Capacity Enhancing grant from CIHR www.icebergs.ubc.ca

\section{5}

\section{AMBULATORY GAS USAGE IN PATIENTS WITH COPD AND EXERTIONAL HYPOXEMIA}

Mika L Nonoyama RT PhD(c) ${ }^{1,2}$, Dina Brooks BSc(PT) PhD ${ }^{1,2,3}$, Gordon H Guyatt MD MSc FCCP ${ }^{4,5}$, Roger S Goldstein MD FRCP FCCP1,6 ${ }^{1}$ Respiratory Diagnostic \& Evaluation Service, West Park Healthcare Centre; ${ }^{2}$ Graduate Department of Rehabilitation Sciences;

${ }^{3}$ Department of Physical Therapy, University of Toronto, Toronto; ${ }^{4}$ Department of Medicine; ${ }^{5}$ Department of Clinical Epidemiology and Biostatistics, McMaster University, Hamilton; ${ }^{6}$ Department of Medicine, University of Toronto, Toronto, Ontario

RATIONALE: Several non-blinded observational studies have described the use of supplemental oxygen during exertion or activities of daily living - ambulatory oxygen - in heterogeneous study populations. This report, based on blinded $\mathrm{N}$-of- 1 randomized controlled trials, characterizes ambulatory gas usage among patients with COPD and exertional hypoxemia. METHODS: Blinded N-of- 1 randomized controlled trials consisted of three pairs of 2-week treatment periods, oxygen for one period of each pair and a placebo for the other. Patient-reported and objective measurements of cylinder and concentrator usage were collected. 
RESULTS: 26 patients completed the study. Patients reported using a median (interquartile range) of 1.3 (1.0 to 2.8) hours of gas per day, closely corresponding to the median recorded machine usage of 1.2 ( 0.8 to 3.1 ) hours of gas per day. Concentrator use (median $=0.8$ hours/day) was significantly greater than cylinder use ( 0.5 hours/day) $(\mathrm{p}=0.02)$. The Bland-Altman analysis shows that patients may underestimate their use by as much 1.9 hours, or overestimate it by as much as 2.4 hours per day. As the duration of gas use increased, the discrepancy between patient-reported and machine measured gas usage increased. CONCLUSIONS: Typical patients with severe COPD and exercise desaturation, used little more than an hour of ambulatory oxygen daily, mostly from concentrators rather than cylinders. Low usage may be due to low activity levels or reluctance to use ambulatory oxygen therapy. The Bland-Altman analysis indicates that individual self report values cannot be used to predict machine gas usage.

Financial Support: Ontario Ministry of Health and Long Term Care

\section{6}

\section{INTERPRETING CHANGES IN ENDURANCE SHUTTLE WALKING PERFORMANCE}

Véronique Pepin ${ }^{1}$, Cynthia Brouillard ${ }^{2}$, Louise Sewell ${ }^{3}$, Sally J Singh $^{3}$, Sue M Revill ${ }^{4}$, Yves Lacasse ${ }^{2}$, François Maltais ${ }^{2}$ ${ }^{1}$ Centre de recherche, Hôpital du Sacré-Coeur de Montréal, Montréal; ${ }^{2}$ Centre de recherche, Hôpital Laval, Québec, Quebec; ${ }^{3}$ Pulmonary Rehabilitation Research Group, Institute for Lung Health, Department of Respiratory Medicine and Thoracic Surgery, Glenfield Hospital, Leicester; ${ }^{4}$ Sherwood Forest Hospitals, Ashfield Community Hospital, Kirby-in-Ashfield, Notts, United Kingdom

RATIONALE: The endurance shuttle walk has recently been shown to be highly responsive to both bronchodilation and pulmonary rehabilitation. The degree to which changes in endurance shuttle walking performance are perceptible to patients is unknown.

OBJECTIVE: To evaluate the relationship between objective and subjective measures of change in endurance shuttle walking performance.

METHODS: 146 comparison points were obtained from 69 patients with COPD $\left(\mathrm{FEV}_{1}: 49 \pm 13 \%\right)$ who completed two or more endurance shuttle walking tests as part of various bronchodilation studies. 137 comparison points were obtained from 137 patients with $\mathrm{COPD}\left(\mathrm{FEV}_{1}: 45 \pm 20 \%\right)$ who completed two endurance shuttle walking tests as part of a pulmonary rehabilitation program. Patients were asked to rate their performance of the day in comparison to their previous performance on a 7 point scale ranging from -3 (large deterioration) to +3 (large improvement). These ratings were related to changes in walking distance and endurance time, expressed both as delta and percent change.

RESULTS: After bronchodilation, patient ratings of change were significantly correlated with delta walking distance $(\mathrm{r}=0.53, \mathrm{p}<0.001)$, delta endurance time $(r=0.55, \mathrm{p}<0.001)$, percent change in walking distance $(\mathrm{r}=0.59, \mathrm{p}<0.001)$, and percent change in endurance time $(\mathrm{r}=0.59$, $\mathrm{p}<0.001)$. After pulmonary rehabilitation, patient ratings of change were significantly correlated with delta walking distance $(r=0.3, p<0.001)$ and delta endurance time $(r=0.37, \mathrm{p}<0.001)$ only.

CONCLUSION: Changes in endurance shuttle walking performance are generally well perceived by patients with COPD. The present study suggests that patients' ability to perceive change after an intervention may be influenced by the type of intervention (bronchodilation, rehabilitation, etc.) and/or by the time delay between measurements. From this set of data, it will be possible to identify the smallest change in walking performance with a high likelihood of being perceived by patients (MCID).

\section{7}

\section{GENDER VARIATION IN ACTIVITY TOLERANCE IN A POPULATION OF CANADIAN ADULTS: THE HUMBOLDT STUDIES}

Donna C Rennie ${ }^{1,2}$, James A Dosman ${ }^{1}$, Joshua A Lawson ${ }^{1}$, Chandima Karunanayake $^{1}$, Punam Pahwa ${ }^{1}$

${ }^{1}$ Canadian Centre for Health and Safety in Agriculture; ${ }^{2}$ College of Nursing, University of Saskatchewan, Saskatoon, Saskatchewan RATIONALE: There is limited study of populations at risk for COPD and the associated respiratory burden.

METHODS: In 2003, a cross-sectional survey was conducted to assess the respiratory health of residents of the town of Humboldt, Saskatchewan (pop.
6000). Lung function ( $\mathrm{FEV}_{1}, \mathrm{FVC}, \mathrm{FEV}_{1} / \mathrm{FVC}$ ratio) was completed during a clinic visit. The self-reported respiratory questionnaire included assessment of breathlessness using the Medical Research Council (MRC) dyspnea scale $(0=$ no breathlessness, $3=$ walking slower than people of the same age on level, and $5=$ too breathless to leave the house or to dress), productive cough, cough and wheeze. The population at risk for COPD was defined as participants over 40 years of age with a history of current or ex-smoking. RESULTS: The overall study population was 2090 adults (response rate $78 \%$ ). In the population over $40,49.4 \%$ had a smoking history. The population at risk for COPD included 751 participants of whom 651 had lung function completed. Of these, there were $8.1 \%$ who had a $\mathrm{FEV}_{1} / \mathrm{FVC}$ ratio of $<0.70$. The distribution of males and females in the population at risk was $52.5 \%$ and $47.5 \%$. There were $27.4 \%$ of participants who reported breathlessness with activity and $10.2 \%$ who stopped for breath when walking at their own pace or who had worse breathlessness (MRC $\geq 3$ ). Women were more likely to have a MRC score of $\geq 3$ ( $<<$ 0.001). Participants (both male and female) with a MRC score $\geq 3$ or more were more likely to wheeze $(p<0.01)$ and cough $(p<0.05)$. Women with a MRC score $\geq 3$ were more likely to have productive coughs $(\mathrm{p}<0.05)$.

CONCLUSION: Although men and women do not differ for being at risk of COPD, women may be more likely to have increased severity of respiratory symptoms.

Funding: CIHR

\section{8}

\section{OPTIMIZING MEDICAL PRACTICE IN COPD: THE RECAP PROJECT}

MF Sedeno BEng MM, M Lebel RN, J Bourbeau MD

Montréal Chest Institute, McGill University, Montréal, Québec

STUDY OBJECTIVES: RECAP (Rehabilitation, Education for COPD, and Added-value to the medical Practice) aimed to optimize COPD medical practice at the McGill University Health Centre (MUHC).

METHODS: We report on a program to improve COPD medical practice introduced in three MUHC hospitals. The program included a priori evaluation of medical practice via chart review. Patients having hospital admissions or emergency room visits due to COPD were selected from a stratified sample size representative of each center (2003-2006). For each patient the care provided for the chronic disease (at discharge) was evaluated and compared to COPD guidelines (CTS, 2003). A model of knowledge translation was used to improve medical practice by implementing specific interventions at each stage of the change process: awareness, agreement, adoption and adherence.

RESULTS: A chart review of 221 patients (mean 74 years, $\mathrm{FEV}_{1} 31 \%$ predicted) showed a number of care gaps: spirometry (only $34 \%$ in 2 of 3 centers), only $21 \%$ patients were on optimal treatment, reference to pulmonary rehabilitation rarely done (34\% referred in 2 of 3 sites) and follow-up in the community (36\%). A program of continuous education was set-up, providing more than 280 hours of training (awareness). Discussion of the care gaps led to the involvement of over 130 health professionals, including respirologists, internists, nurses and managers (agreement and adoption). As a result, new quality practice indicators have been adopted and integrated to the MUHC accreditation; thus to assure the sustainability of the improvement process beyond the RECAP project (adherence).

CONCLUSIONS: The RECAP project has obtained organizational commitment to implement a quality process, including practice indicators to enhance COPD care at the MUHC.

Funded By: Agence de santé et des services sociaux (ASSS) de Montréal and an unrestricted educational grant of a consortium of the pharmaceutical industry (GlaxoSmithKline, Pfizer, Boehringer-Ingelheim, and Bristol Myers Squibb)

\section{9}

\section{THE SENSEWEAR ARM BAND YIELDS VALID AND RESPONSIVE MEASUREMENTS OF ENERGY EXPENDITURE IN PATIENTS WITH COPD}

Kylie Hill1,2, Thomas Dolmage ${ }^{2,3}$, Lynda Woon ${ }^{2,4}$, Roger Goldstein 1,2,3,5, Dina Brooks ${ }^{1,2}$

${ }^{1}$ Department of Physical Therapy, University of Toronto; ${ }^{2}$ Respiratory Medicine, ${ }^{3}$ Respiratory Diagnostic and Evaluation Services, ${ }^{4}$ Physiotherapy Department, West Park Healthcare Centre, ${ }^{5}$ Department of Medicine, University of Toronto, Toronto, Ontario RATIONALE: Although optimizing functional performance is considered a key goal of pulmonary rehabilitation, obtaining objective measures 
of functional performance is challenging as this construct encompasses physical, psychological, social, occupational and spiritual activities. Measures of energy expenditure may be a surrogate marker of functional performance. Bodymedia Inc has recently developed the Sensewear Arm Band $^{\mathrm{TM}}(\mathrm{SAB})$, a light weight and comfortable device that claims to measure energy expenditure. As the validity of measurements obtained during activities of daily living using the SAB has not been established in COPD patients, the aim of this study was to compare them with direct measurements of gas exchange collected using a portable telemetric gas analysis system (Cosmed K4b ${ }^{2 \mathrm{TM}}$ ).

METHODS: Ten subjects with COPD ( $\mathrm{FEV}_{1}=58 \pm 29 \% ; 6$ males $)$ spent 6 minutes in five "experimental conditions"; supine, sitting, standing and walking at two self-selected paces. Throughout each experimental condition, they wore both the SAB and Cosmed $\left(\mathrm{K}_{4} \mathrm{~b}^{2 \mathrm{TM}}\right)$. Measurements of METS were compared using repeated measures analysis of variance (2 within-subject factors).

RESULTS: (METS; mean \pm SD).

\begin{tabular}{lccccc} 
& Supine & Sitting & Standing & Slow walk & Fast walk \\
\hline SAB & $0.9 \pm 0.1$ & $0.9 \pm 0.1$ & $1.0 \pm 0.2$ & $2.7 \pm 0.5$ & $3.2 \pm 0.5$ \\
Cosmed & $1.0 \pm 0.2$ & $1.1 \pm 0.2$ & $1.2 \pm 0.2$ & $2.9 \pm 0.5$ & $3.4 \pm 0.6$ \\
\hline
\end{tabular}

The change in METS between the "experimental conditions" was similar for both devices (no significant main effect)

CONCLUSIONS: Compared with measurements obtained using the Cosmed, the SAB may underestimate energy expenditure in patients with COPD. Nevertheless, these data suggest that the SAB yield measurements of energy expenditure that are consistent with the intensity of physical activity. Financial support: National Sanitarium Association, Great West Life Fund

\section{PEDIATRICS STREAM}

\section{0}

\section{DIAGNOSIS OF PEDIATRIC ASTHMA USING NUCLEAR MAGNETIC RESONANCE ANALYSIS OF URINE}

Erik J Saude PhD ${ }^{1,2}$, Christopher Skappak ${ }^{1}$, Brian D Sykes PhD², Brian Rowe $\mathrm{MD}^{3}$, Darryl J Adamko MD FRCPC ${ }^{1}$

${ }^{1}$ Departments of Pediatrics, ${ }^{2}$ Biochemistry, and ${ }^{3}$ Emergency Medicine, Medical Resonance Diagnostics Centre (MRDC) University of Alberta and Stollery Children's Hospital, Edmonton, Alberta

BACKGROUND: Asthma is a chronic inflammatory disease of the airways leading to airway obstruction. The inflammation found in patients with asthma has a unique makeup of immune cells like eosinophils, basophils and mast cells. Management of this inflammation requires antiinflammatory drugs like inhaled corticosteroids. Determining when to start, or adjust, inhaled corticosteroid dosages requires an accurate knowledge of the patient's current level of airway inflammation. Existing methods for determining inflammation levels (i.e. sputum analysis, exhaled nitric oxide, and bronchoscopy) are not practical for all patients, especially the very young. Thus, the level of inflammation is often inferred from patient symptoms or lung function tests. One-dimensional nuclear magnetic resonance spectroscopy (NMR) identifies metabolites in solution based on their particular nuclear spin characteristics. We hypothesized that the unique airway inflammation found in asthma creates distinct metabolic products that may be identified in the urine.

OBJECTIVE: To determine whether children with asthma have a distinct urine metabolic profile that could be measured in a non-invasive urine sample using NMR analysis.

METHODS: Clinical information and urine samples were collected from the Stollery Children's Hospital pediatric outpatient asthma clinic and the Emergency Department (46 and 20 children respectively, ages 4-16). By chart review age, sex, history/physical exam, medication dosage, atopic status, and lung function from each visit were collected in order to correlate clinical presentation with urine NMR data. Urine spectra were collected on a $600 \mathrm{MHz}$ spectrometer and concentrations of metabolites were determined by Chenomx NMR Suite software.

RESULTS: Based on 50 urine metabolites, multivariate statistical analysis separated the urine profiles of age and sex-matched healthy control children from those in an asthma outpatient clinic and/or emergency room. CONCLUSION: While this work is still preliminary, we believe NMR analysis of urine offers the potential for non-invasive diagnosis and monitoring of airway disease in patients of any age.

This Abstract is funded by: AllerGen, Sick Kids Foundation, and AHFMR

\section{1}

RELATIONSHIPS BETWEEN EARLY NITROGEN DIOXIDE, ETS, AND ALLERGEN EXPOSURES ON AIRWAY DISEASE IN A HIGH RISK COHORT

C Carlsten MD MPH ${ }^{1 *}$, H Dimich-Ward PhD ${ }^{1}$, M Brauer ScD ${ }^{1}$, A Dybuncio ${ }^{1}$, AB Becker ${ }^{2}, M$ Chan-Yeung ${ }^{3}$

${ }^{1}$ University of British Columbia; Vancouver General Hospital, Vancouver, British Columbia

OBJECTIVE: To quantify, in a high-risk birth cohort, the effect of early exposure to inhaled gases and particles (nitrogen dioxide $\left[\mathrm{NO}_{2}\right]$, fine particulate matter $\left[\mathrm{PM}_{2.5}\right]$ environmental tobacco smoke [ETS]), alone or in combination with animal allergens, on diverse respiratory endpoints.

METHODS: A cohort of infants at high risk for asthma was recruited before birth in Vancouver and Winnipeg, Canada for a study of an intervention for the primary prevention of asthma. Home levels of bedroom $\mathrm{NO}_{2}$ and allergens (dog, cat, and house dust mite), urinary cotinine:Cr, and nasal RSV status were determined during year 1; cord blood cotinine (CCot) was also measured at the time of birth, while atopy was determined at age 1. Year 1 ambient $\mathrm{NO}_{2}$ and $\mathrm{PM}_{2.5}$ were determined by land use regression. At 7 years, the children were assessed for asthma and allergic rhinitis by pediatric allergists and bronchial hyperreactivity (BHR) was assessed by methacholine challenge. Stepwise MLR was used to determine odds ratios for main effects of each exposure and for combined exposures. Sensitivity analyses were performed.

SUMMARY OF RESULTS: Asthma, BHR, and rhinitis were common at 7 years. Combined exposure to dog allergen plus $\mathrm{NO}_{2}$, ETS (CCot) or RSV conferred increased risk for asthma (relative to the risk in those having neither such exposure). Atopy was generally a stronger risk factor for these outcomes than the non-allergen exposures alone. However, exposure to non-allergen exposures (particularly ETS) appeared to increase the risk due to atopy for these outcomes. Early exposure to outdoor air pollution, particularly $\mathrm{PM}_{2.5}$ conferred increased risk for these outcomes, particularly asthma. Funded By: Canadian Institutes of Health Research

\section{2}

DELIVERY OF MEDICATION VIA A NOVEL NONELECTROSTATIC VALVED HOLDING CHAMBER (VHC) FOR INFANT USE DEPENDS ON THE NUMBER OF INHALATIONS

Howard Harkness, MW Nagel, K Wiersema, C Doyle, J Mitchell Trudell Medical International, London, Ontario

RATIONALE: The tidal volumes $\left(\mathrm{V}_{\mathrm{t}}\right)$ of infants prescribed a $\mathrm{VHC}$ to assist in the delivery of medication via pressurized metered-dose inhaler (pMDI) are typically smaller than the space enclosed by the chamber. The number of inhalations after actuating the pMDI before removing the mask from the infant's face will therefore influence the mass of medication delivered. Under such circumstances a flow visualization aid is advantageous for the care giver to count the number of inhalations that are needed to optimize medication delivery.

METHODS: Delivery of fluticasone propionate (Flixotide ${ }^{\circledR}$-HFA, GSK plc, UK; $125 \mu \mathrm{g} /$ actuation) via 198-ml non-electrostatic VHCs (AeroChamber $\mathrm{Max}^{\circledR}$, Trudell Medical International, Canada) with infant facemask ( $\mathrm{n}=3$ devices $\times 3$ replicates) was evaluated using an infant face model with soft tissue modeling around chin and cheeks that enables the correct force to be applied to seal the mask to the face. Filter collection took place behind the lips of the model to determine total emitted mass after 1, 2, 3, 4, 5 and 6 breathing cycles, with the filter connected to a breathing simulator set up to mimic use by a 9-month old infant $\left(\mathrm{V}_{\mathrm{t}}=50-\mathrm{ml}\right.$; rate $=30$ cycles $/ \mathrm{min}$; duty cycle $\left.=0.25\right)$.

RESULTS: Total mass increased progressively with number of inhalations as the VHC was emptied of aerosol. Thus total mass/actuation (mean $\pm \mathrm{SD}$ ) was $7.9 \pm 1.6 \mu \mathrm{g}, 12.1 \pm 2.1 \mu \mathrm{g}, 13.9 \pm 2.5 \mu \mathrm{g} ; 19.2 \pm 2.7 \mu \mathrm{g} ; 23.4 \pm 3.7 \mu \mathrm{g}$ and $25.3 \pm 3.8 \mu \mathrm{g}$ after $1,2,3,4,5$ and 6 inhalations respectively. 
CONCLUSIONS: The Flow- $\mathrm{Vu}^{\circledR}$ inspiratory flow indicator provided with this VHC provides the care giver with the capability to count the number of inhalations when administering medication to infants, allowing 5-6 breaths after pMDI actuation in accordance with manufacturer instructions. This indicator would also be a valuable clinical tool to ensure that these patients receive all the medication available to them.

Financial support: Trudell Medical International

\section{3}

\section{EFFECTIVENESS OF MONTELUKAST ON CAREGIVER QUALITY OF LIFE IN CHILDHOOD ASTHMA}

N Harvey, AB Becker, S Foucart, F Psaradellis, JS Sampalis, D Bérubé On behalf of the ACTION3 investigators

BACKGROUND: The Pediatric Asthma Caregiver's Quality of Life Questionnaire (PACQLQ) measures the limitations and anxieties faced by caregivers of children with asthma. The aim was to evaluate the change in QoL of caregivers when adding montelukast to ICS in uncontrolled asthmatic children.

METHODS: A 12-week open-label, prospective cohort study. Eligible patients included children aged 2-14 years who are treated with ICS and have uncontrolled asthma (Canadian Asthma Consensus Guidelines). Patients 6-14 years old were treated with montelukast $5 \mathrm{mg}$ QD and those aged 2 to less than 6 years were treated with $4 \mathrm{mg} Q D$. The primary outcome measure included the absolute change in the PACQLQ score between baseline, 4 and 12 weeks of treatment. The 13 item PACQLQ was measured on a 7-point Likert scale and is comprised of two domains: activity limitations and emotional function. The PACQLQ score is calculated as the mean of all items and ranges between 1 (severe impairment) and 7 (no impairment). RESULTS: The intent-to-treat population included 383 patients, of which $358(93.5 \%)$ and $329(85.9 \%)$ completed 4 and 12 weeks of treatment. The mean (SD) age was 6.9 (3.3) years. The mean (SD) PACQLQ score increased from $4.98(1.43)$ at baseline to $6.03(1.16)$ at 4 weeks and 6.33 (0.97) at 12 weeks. The absolute mean (SD) change in PACQLQ of 1.06 $(1.25)$ at 4 weeks and $1.32(1.33)$ at 12 weeks were clinically (PACQLQ>0.7) and statistically significant $(\mathrm{P}<0.001)$. Both domains showed statistically significant PACQLQ changes $(\mathrm{P}<0.001)$ with a mean $(\mathrm{SD})$ increase of 1.02 (1.49) and 1.38 (1.60) for activity limitations and of 1.07 (1.30) and 1.29 (1.37) for emotional function at 4 and 12 weeks respectively.

CONCLUSION: The effect of montelukast as a controller monotherapy or in conjunction with ICS showed significant improvement on the quality of life of caregiver of children who had previously uncontrolled asthma.

\section{4}

\section{EFFECTIVENESS OF MONTELUKAST IN CHILDREN WITH UNCONTROLLED ASTHMA AND A HISTORY OF VIRAL INDUCED ASTHMA EXACERBATIONS}

AB Becker, N Harvey, S Foucart, F Psaradellis, JS Sampalis, $D$ Bérubé, On behalf of the ACTION3 investigators

BACKGROUND: Viral infections are involved in about $80 \%$ of asthma exacerbations in children and often require medical intervention thus resulting in a significant burden of illness.

OBJECTIVES: This study examined the effectiveness of montelukast for the treatment of children who have uncontrolled asthma and a medical history of virally induced asthma exacerbations. The Pediatric Asthma Caregiver's Quality of Life Questionnaire (PACQLQ) score was assessed. METHODS: A 12-week open-label, prospective cohort study where children ( 2 to 14 years) with uncontrolled asthma were included whether treated with ICS or untreated. Uncontrolled asthma was defined according to the Canadian Asthma Consensus Guidelines. All patients received montelukast $4 \mathrm{mg}$ or $5 \mathrm{mg} \mathrm{QD}$ at bedtime for 12 weeks in addition to their ICS. Of the 385 patients enrolled, 163 identified viral infection as their primary trigger for asthma exacerbations and were included in this analysis. Efficacy outcome measures included the absolute change in the Asthma Control Questionnaire (ACQ) score between baseline and 12 weeks of treatment, and the proportion of patients with an ACQ score $<1.5$. Secondary outcome measures included the absolute change in PACQLQ score.

RESULTS: The mean (SD) ACQ score changed from $1.66(1.00)$ at baseline to $0.54(0.73)(\mathrm{P}<0.001)$ at 12 weeks. The mean $(\mathrm{SD})$ decrease in
ACQ at 12 weeks was 1.10 (1.10), this change was clinically and statistically significant. There were $128(90.8 \%)$ patients controlled $(\mathrm{ACQ}<1.5)$ at week 12. The mean (SD) PACQLQ score increased from $4.81(1.50)$ at baseline to $6.27(0.96)$ at 12 weeks. The mean (SD) increase in PACQLQ score at week 12 was 1.46 (1.36). This change was clinically (PACQLQ $>0.7)$ and statistically $(\mathrm{P}<0.001)$ significant.

CONCLUSION: Montelukast is effective as a controller monotherapy or in conjunction with ICS in children with uncontrolled asthma with a history of viral induced asthma exacerbations.

\section{5}

\section{THE EFFECT OF TOBACCO SMOKE EXPOSURE ON THE RELATIONSHIP BETWEEN ENDOTOXIN AND LUNG FUNCTION IN CHILDREN AND ADOLESCENTS WITH OR WITHOUT ASTHMA AND WHEEZE}

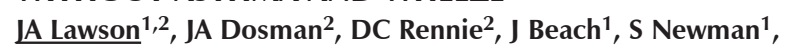
A Senthilselvan ${ }^{1}$

${ }^{1}$ Department of Public Health, School of Public Health, University of Alberta, Edmonton, Alberta; ${ }^{2}$ Canadian Centre of Health and Safety in Agriculture, University of Saskatchewan, Saskatoon, Saskatchewan

RATIONALE: The relationship between tobacco smoke exposure, endotoxin and lung function has not been well studied. We examined the relationship between endotoxin and lung function in a population of 6 to 18 year olds with and without asthma and wheeze accounting for tobacco smoke exposure.

METHODS: A case-control study was completed in Humboldt, Saskatchewan and surrounding area during 2005-2007. Cases comprised subjects reporting doctor-diagnosed asthma or wheeze in the past year. Two control subjects without asthma or wheeze were randomly selected per case. Data included disease and some exposure information by questionnaire, endotoxin levels from vacuumed dust (child's play area floor and mattress), tobacco smoke exposure based on salivary cotinine, and lung function from spirometry. Regression analyses for lung function were conducted with age, age $^{2}$, sex, height, case-control status, endotoxin and tobacco smoke exposure as independent variables. Interaction between these variables was assessed.

RESULTS: Among those contacted and eligible, $42.0 \%$ took part and were included in the analysis (102 cases, 207 controls). Females constituted $35.3 \%$ of cases and $60.4 \%$ of controls. Among controls with high tobacco smoke exposure there was an inverse association $(\mathrm{p}=0.01)$ between endotoxin (EU/mg) and peak expiratory flow rate (PEFR). Among cases with high tobacco smoke exposure, there was an inverse association between play area endotoxin $\left(\mathrm{EU} / \mathrm{m}^{2}\right)$ and forced vital capacity $(\mathrm{p}=0.09)$ but a positive association between mattress endotoxin (EU/ $\mathrm{mg}$ ) and PEFR ( $\mathrm{p}=0.07)$. Also, among female cases, there was a statistically significant inverse association $(\mathrm{p}=0.002)$ between mattress endotoxin $\left(\mathrm{EU} / \mathrm{m}^{2}\right)$ and forced expiratory volume at 1 second.

CONCLUSIONS: The relationship between endotoxin and lung function appears to be modified by tobacco smoke exposure and sex and may differ between subjects with and without asthma and wheeze. By studying these relationships, the effects of the indoor environment on children may be assessed and possible strategies to minimize morbidity implemented. Funding: Canadian Institutes of Health Research

\section{6}

\section{INFANT LUNG FUNCTION IN A COHORT OF INFANTS AFTER SEVERE WHEEZING ILLNESS}

\section{P Subbarao, S Balkovec, C Keast, F Ratjen}

Division of Respiratory Medicine, Hospital for Sick Children,

University of Toronto, Toronto, Ontario

INTRODUCTION: Infants with severe wheezing illnesses are thought to be at higher risk for the development of asthma. However a proportion of these infants have self-resolving wheezing illnesses that do no respond to typical anti-asthma treatment. We propose to study infants with a history of severe wheezing illness to prospectively document their degree of lung dysfunction and response to bronchodilators and to follow their course with repeat lung function.

METHODS: Infants who had been hospitalized or received oral steroids 
for wheezing illnesses were recruited into the study. We recorded plethysmographic lung volumes and forced expiratory volumes using raised volume rapid thoracoabdominal compression techniques.

RESULTS: Thus far 14 infants (aged 22-114 weeks, 11 male), have been enrolled in this study. Six infants have returned for two visits. The mean $z$-score for FEV0.5 was $0.43(95 \% \mathrm{CI}-0.1,0.75)$ for the baseline visit and 0.21 $(95 \%$ CI $-0.14,0.56)$ for the six infants at their second visit. Three infants had FEV0.5 $z$-scores $<-1.5$. The baseline and follow-up mean FEF2575 z-scores [baseline -1 ( $95 \%$ CI -2,0.01), follow-up - 0.56 (95\% CI - 1.3, 0.2)] and mean FEF85 z-scores [baseline -1.5 (95\% CI $-2.1,-0.8)$, follow-up $-1.3(95 \%$ CI $-2.1,-0.4)$ ] values showed a greater degree of dysfunction. Lung volumes (FRC $z$-scores) were elevated at baseline [1.89 (95\% CI 1.6, 2.2)] and follow-up [1.1 $(95 \% \mathrm{CI} 0.8,1.4)]$. The group as a whole did not have a significant response to bronchodilators at either the baseline or follow-up visit.

CONCLUSION: Infants post severe wheezing illness have normal FEV0.5 but decrements in their small airways measures. They also have elevated lung volume measurements. These data support the theory that the focus of injury in wheezing illness is in the small airways. Further recruitment and follow-up is required to determine whether infants with severe wheezing illness develop asthma.

\section{7}

\section{DOES THE PROVISION OF A WRITTEN ACTION PLAN IN}

THE EMERGENCY DEPARTMENT (ED) IMPROVE ADHERENCE TO PHYSICIANS' RECOMMENDATIONS AND ASTHMA CONTROL IN CHILDREN WITH ACUTE ASTHMA? A RANDOMIZED CONTROLLED TRIAL

$\underline{\text { R Zemek MD }}{ }^{1}$, FM Ducharme MD², D Chalut MD $^{2}$, D McGillivray $\mathrm{MD}^{2}$, FJ Noya $\mathrm{MD}^{2}$, Sandy Resendes $\mathrm{MA}^{2}$, Linyan Meng $\mathrm{MSc}^{2}$, Lyudmyla Khomenko PhD², Rachel Rouleau BPharm $\mathrm{MSc}^{3}$, Xun Zhang PhD $^{4}$

${ }^{1}$ Department of Pediatrics, Children's Hospital of Eastern Ontario, University of Ottawa, Ottawa, Ontario; ${ }^{2}$ Department of Pediatrics, McGill University Health Centre, Montréal; ${ }^{3}$ Centre de santé et de services sociaux de la Vieille Capitale, Québec; ${ }^{4}$ Research Institute, McGill University Health Centre, Montréal, Québec

BACKGROUND: There is generally poor adherence to therapy, medical follow-up, and asthma education recommendations following ED visits for acute asthma.

OBJECTIVE: To examine the efficacy of written action plan coupled with prescription (WAP-P) compared to usual prescription (UP) on adherence to discharge recommendations and asthma control in children with acute asthma. DESIGN/METHODS: We conducted a RCT of children (1-17 years) treated for acute asthma in the ED. Children were randomized to receive WAP-P or UP. All received fluticasone and albuterol inhalers fitted with dose counters to be used per ED physician discretion. The main outcome was adherence to fluticasone over the next 28 days (used/recommended). Secondary outcomes included pharmacy dispensation of oral steroids, rescue $\beta 2$-agonist use, medical follow-up, asthma education, acute care visits, and asthma control.

RESULTS: We randomized 219 (109 WAP-P, 110 UP) children aged 1-6 yrs (78\%), 7-12 yrs (19\%) and 13-17 yrs (3\%). Compared to UP, WAP-P use increased physicians' advice to continue daily fluticasone at least until medical follow-up $(33 \%$ vs. $12 \%, \mathrm{p}<0.001)$, and to schedule medical follow-up ( $83 \%$ vs. $44 \%, p<0.0001$ ). Children receiving WAP-P showed no difference in adherence to recommended fluticasone in the initial 14 days $(\mathrm{N}=211: 67 \%$ vs. $62 \%, \mathrm{P}=0.2)$ but significantly higher in the last 14 days ( $\mathrm{N}=98,50 \%$ vs. $34 \%, \mathrm{p}=0.03$ ), with greater proportion filling oral steroid prescriptions ( $73 \%$ vs. $56 \%, p=0.03$ ) than UP group. There were no group differences in rescue $\beta 2$-agonist use, medical follow-up, asthma education, and acute care visits. At 28 days, the WAP-P group reported fewer indicators of poor control (2.0 vs. $1.5, \mathrm{p}<0.05)$.

CONCLUSION: In children with acute asthma, use of WAP-P increased adherence to prescribed oral and inhaled steroids and improved asthma control, compared to UP. It also increased physicians' recommendation for maintenance preventative therapy and medical follow-up.

\section{OTHER STREAM}

\section{8}

THE EFFECT OF EARLY AMBULATION ON THE FREQUENCY OF PULMONARY EMBOLUS FOLLOWING DIAGNOSIS OF A DEEP VEIN THROMBOSIS: A SYSTEMATIC REVIEW

CM Anderson $^{1}$, TJ Overend ${ }^{1,2}$, J Godwin $^{2}$, C Sealy ${ }^{2}$, A Sunderji $^{2}$ ${ }^{1}$ London Health Sciences Centre; and ${ }^{2}$ School of Physical Therapy, University of Western Ontario, London, Ontario

RATIONALE: Is it safe to mobilize patients who present with a deep vein thrombosis (DVT)? There is uncertainty among health care providers as to whether ambulation may dislodge DVTs, possibly leading to a pulmonary embolism (PE), or whether ambulation is appropriate given the wellestablished systemic effects of exercise. Thus we systematically reviewed the effects of early ambulation on development of PE and progression or development of a new thrombus in patients with acute DVT.

METHODS: Medline, PubMed, CINAHL, Embase, PEDro and Cochrane Review databases were searched for randomized control trials (RCTs) from inception to September 2007. Two reviewers independently reviewed each paper before meeting to reach consensus. The Jadad scale and PEDro criteria were used to appraise study quality.

RESULTS: While 11 RCTs were identified, only four were accepted for analysis. Meta-analysis was carried out where study designs and outcomes were appropriate. Results were reported as odds ratios and 95\% confidence intervals. For development of a $\mathrm{PE}$, the pooled odds ratios for ambulation and compression versus bed rest and compression (OR, 0.56 [95\%CI, 0.26-1.20]), and ambulation and compression versus bed rest (OR, 1.41 [95\%CI, 0.53 3.79]) were not significant. For progression or development of a new DVT, the independent odds ratios for ambulation and compression versus bed rest (OR, 0.43 [95\%CI, 0.09-2.03]), and ambulation and compression versus bed rest and compression (OR, 0.33 [95\%CI, 0.10-1.14]) were not significant. CONCLUSIONS: There were conflicting results for development of a PE. For progression or development of a new DVT, the evidence suggests that there is less risk with ambulation, however further studies on this question are required.

\section{9}

\section{CHALLENGES TO TUBERCULIN SCREENING AND FOLLOW-UP IN AN URBAN ABORIGINAL SAMPLE IN MONTREAL, CANADA}

Paul Brassard $^{1,2}$, Kelly K Anderson ${ }^{1}$, Kevin Schwartzman ${ }^{2,3}$, Mary Ellen Macdonald ${ }^{4,5}$, Dick Menzies ${ }^{2,3}$

${ }^{1}$ Department of Medicine, Division of Clinical Epidemiology; ${ }^{2}$ Montreal Chest Institute; ${ }^{3}$ Respiratory Epidemiology Unit, McGill University Health Centre; ${ }^{4}$ School of Nursing; ${ }^{5}$ Department of Oncology, McGill University, Montreal, Quebec

BACKGROUND: Tuberculosis (TB) incidence rates in Canadian Aboriginal peoples are substantially higher than the general population. Health problems faced by Aboriginal people are compounded when migrating to urban areas.

OBJECTIVE: We sought to describe the prevalence and predictors of tuberculin skin test (TST) reactors in a high-risk sample of urban Aboriginal people, and to evaluate adherence to medical evaluation and latent tuberculosis infection (LTBI) treatment among those with TST reactivity.

DESIGN: We obtained a convenience sample of high-risk Aboriginal peoples in Montreal and administered a one-stage TST. Financial compensation ( $\$ 10 \mathrm{CAD}$ ) was provided for participation in the TST screening and an interview, and again for returning for TST reading within 48 to 72 hours.

RESULTS: Of the 164 participants tested, $86 \%$ returned for TST reading. Positive TST reactions $(\geq 10 \mathrm{~mm})$ were observed in $17.7 \%(25 / 141,95 \% \mathrm{CI}$ 11.4-24.0) of participants, and were associated with older age (OR per 10 year increase 1.8, 95\%CI 1.2-2.7) and Inuit Aboriginal group (OR 2.8, $95 \%$ CI 1.1-7.3). We attempted to refer all individuals with TST reactivity for medical evaluation, a step for which participants were not compensated. Only four participants presented for evaluation, of whom one initiated and none completed LTBI treatment.

CONCLUSION: Tuberculin screening in this population can be an effective strategy for identifying TST reactive individuals; however, screening efforts will 
have minimal impact without additional efforts in this high-risk group. A costing exercise indicates that the provision of financial compensation for medical evaluation and treatment may be one cost-effective strategy for improving adherence and subsequently preventing cases of active $\mathrm{TB}$ in addition to addressing other barriers to health care faced by urban Aboriginal people.

\section{0}

\section{LUNG GENE THERAPY FOR CYSTIC FIBROSIS: GETTING THE RIGHT DELIVERY SYSTEM TO MOVE FROM MICE TO NEWBORN "MEN"}

AL Coates, K Leung, E Louca, DR Koehler, H Cao, J Hu

The Hospital for Sick Children, University of Toronto, Toronto, Ontario RATIONALE: While lung gene therapy remains the most definitive potential treatment of cystic fibrosis (CF), the early encouraging studies have been done in mice. The introduction of newborn screening will mean the diagnosis in small infants before the development of lung disease, the ideal candidates for gene therapy. However, the transition from very small animals to human has considerable challenges, especially when it comes to gene delivery. The purpose of this study was to develop a more efficient and predictable way to deliver aerosol to the deep lung of rabbits with body weights similar to newborn humans.

METHODS: The Aeroprobe ${ }^{\mathrm{TM}}$ INC with its LABneb Catheter Control Unit $^{\mathrm{TM}}$ (CCU) (Trudell Medical International, London, Ontario) is a multi-lumen $1 \mathrm{~m}$ long catheter with an external diameter of $2.9 \mathrm{~mm}$ that tapers to a $0.75 \mathrm{~mm}$ tip that can be mounted in the center of an endotracheal tube. In the anesthetized rabbit, the LABneb ${ }^{\mathrm{TM}} \mathrm{CCU}$ can also double as a ventilator allowing for the delivery of aerosol using a constant flow only on inspiration, hence eliminating loss during the expiratory phase. This system was used to deliver a viral vector solution made of helper dependent adenovirus (HD-Ad) using an epithelial cell specific promoter expressing the lacZ reporter gene.

RESULTS: The MMD of the droplets produced by the catheter measured by laser diffraction was $12.6 \pm 0.32 \mu \mathrm{m}$, with $89 \%$ active viral particles per $\mathrm{mL}$ of solution recovered post nebulization. The vector solution was delivered using the AeroProbe ${ }^{\mathrm{TM}} \mathrm{INC}$ to intubated and anaesthetized rabbits. Gene expression $(n=6)$ was seen down to the level of the terminal bronchioles, with specificity in the epithelial cells, including goblet cells.

CONCLUSIONS: This delivery system, developed in rabbits would be very practical for gene newly diagnosed infants and easily adaptable for delivery through a bronchoscope in larger patients.

Supported by the Canadian Cystic Fibrosis Foundation and AeroProbe ${ }^{\mathrm{TM}}$ INC supplied by Trudell Medical International

\section{1}

\section{PULMONARY ENDARTERECTOMY FOR CHRONIC THROMBOEMBOLIC PULMONARY HYPERTENSION (CTEPH): RESULTS FROM A CANADIAN CENTER SPECIALIZING IN THE EVALUATION OF PATIENTS WITH END-STAGE LUNG DISEASES}

Marc de Perrot, Karen McRae, Yaron Shargall, Elie Fadel, Kong Teng Tan, Susanna Mak, Peter Slinger, Narinder Paul, John Thenganatt, John Granton

Toronto General Hospital, University of Toronto, Toronto, Ontario INTRODUCTION: Improvement in surgical techniques and patient selection has made pulmonary endarterectomy (PEA) the treatment of choice for patients with CTEPH. We recently initiated a PEA program in our institution and present our experience with the first 22 patients evaluated in our program.

METHODS: The diagnosis of CTEPH was made in the presence of elevated pulmonary artery (PA) systolic pressure on echocardiogram and mismatched segmental perfusion defect on lung ventilation-perfusion scan. Evaluation was completed with pulmonary angiogram and right heart catheterization after at least 12 weeks of anticoagulation. Pulmonary hypertension $(\mathrm{PH})$ was defined as PA mean pressure $>25 \mathrm{mmHg}$ at rest. RESULTS: Out of 22 patients, 15 underwent PEA and 7 were treated medically because of distal disease (obstruction located beyond the division of the PA segmental branches). Preoperative mean PA pressure ranged between 43 and 74 (median 48) $\mathrm{mmHg}$ and cardiac index ranged between 1.2 and 3.9 (median 1.8 ) L/min/ $/ \mathrm{m}^{2}$. Total pulmonary resistance decreased from 933 (range, 493-2545) preoperatively to 374 (range, 240-819) Dynes.sec.cm -5 postoperatively $(\mathrm{p}<0.0001)$. Total circulatory arrest time ranged between 23 and 51 (median 32) minutes. One patient underwent combined mitral valve replacement and PEA. Nine patients were extubated within 48 hours after surgery. One patient died after emergent surgery for an overall in-hospital mortality of $6.7 \%$. The PA systolic pressure decreased from $92 \pm 30 \mathrm{mmHg}$ preoperatively to $43 \pm 14 \mathrm{mmHg}$ at 6 months follow-up on echocardiogram $(\mathrm{p}<0.0001)$ and 6' walk test improved from $324 \pm 196 \mathrm{~m}$ to $478 \pm 117 \mathrm{~m}(\mathrm{p}<0.05)$. NYHA dyspnea class improved from $3.4 \pm 0.7$ preoperatively to $1.4 \pm 0.5$ at 6 months follow-up.

CONCLUSIONS: PEA can be safely performed in experienced centers and is an important therapeutic option for selected patients with end-stage $\mathrm{PH}$.

\section{2}

\section{PRETREATMENT WITH ORAL DOXYCYCLINE MODERATES THE INCREASED MMP-9 ACTIVITY INDUCED BY BOTH LOW AND HIGH VOLUME MECHANICAL VENTILATION IN A RAT MODEL}

Thomas S Hurst $^{1}$, J Fert-Bober ${ }^{2}$, DH Johnson ${ }^{3}$, G Sawicki ${ }^{2}$

${ }^{1}$ Department of Medicine; ${ }^{2}$ Department of Pharmacology, University of Saskatchewan, Sasktatoon, Saskatchewan;

${ }^{3}$ Department of Medicine, University of Alberta, Edmonton, Alberta INTRODUCTION: While low volume/pressure mechanical ventilation is preferred over higher volume/pressure it is sometimes necessary to use higher volumes to maintain adequate oxygenation. Using a rat model we have earlier shown that high volume ventilation produced higher lung MMP-9 activity compared to low volume. It is known that doxycycline inhibits MMP synthesis in vitro. We wished to ascertain whether pretreatment with oral doxycycline would ameliorate the increase in MMP activity which results from high volume mechanical ventilation.

METHODS: We mechanically ventilated 4 groups of 10 anesthetized rats (mean body weight $330 \mathrm{gm})$ using either low $(7.5 \mathrm{~mL} / \mathrm{kg})$ or high $(30 \mathrm{~mL} / \mathrm{kg}$ ) tidal volumes for 20 minutes. We then either sacrificed them immediately or ventilated for a further 240 minutes of low $(7.5 \mathrm{~mL} / \mathrm{kg})$ tidal volume ventilation before sacrifice. A further 4 groups were similarly ventilated following pretreatment with oral doxycycline $(2 \mathrm{mg} / \mathrm{kg}$ bd). The animals were sacrificed and tissues frozen for later analysis. MMP activities were measured using zymography.

RESULTS: MMP-9. There were significant $(\mathrm{p}<0.05)$ differences in activity between groups ventilated for 20 minutes versus 240 minutes regardless of tidal volume or doxycycline treatment. There was a significantly lower level of activity in the doxycycline treated group versus controls in both the low $(570 \pm 85 \mathrm{v} 171 \pm 44)$ and the high tidal volume groups $(814 \pm 120 \mathrm{v} 475 \pm 28)$.

MMP-2. There were no significant differences between any of the groups. CONCLUSION: MMP-9 activity is clearly increased following $240 \mathrm{~min}$ utes of low volume ventilation demonstrating that any artificial ventilation has "negative" consequences. These consequences are worsened by higher tidal volumes/pressure. The mitigation of this effect by doxycycline opens an avenue for investigation into the potential use of MMP inhibitors as preventive treatment or therapy.

Funding: Lung Association of Saskatchewan

\section{3}

PREVALENCE AND CONTROL OF CARDIOVASCULAR RISK FACTORS IN LUNG TRANSPLANT RECIPIENTS

James C Johnston ${ }^{1}$, Robert D Levy ${ }^{1,2}$, John Yee $^{2,3}$, Nilu Partovi ${ }^{3,4}$, Jane Kerr' ${ }^{2}$, Jennifer M Wilson ${ }^{1,2}$

${ }^{1}$ Department of Medicine, University of British Columbia; ${ }^{2}$ British Columbia Transplant Society; ${ }^{3}$ Department of Surgery; ${ }^{4}$ Faculty of Pharmaceutical Sciences, University of British Columbia, Vancouver, British Columbia

RATIONALE: Cardiovascular risk factors are reported to be highly prevalent in lung transplant recipients. We reviewed the prevalence and control of certain modifiable risk factors, including obesity, diabetes, hypertension, and hyperlipidemia in lung transplant recipients currently followed in our program.

METHODS: Obesity was defined as a Body Mass Index $>30$ on the most recent measurement. Diabetes control was defined as a glycated hemoglobin level $<7.0 \%$. Hypertension was defined as antihypertensive medication use 
or blood pressure $(\mathrm{BP})>130 / 80$ in a diabetic or $>140 / 90$ in a non-diabetic patient on the most recent measurement. Uncontrolled hypertension was defined as antihypertensive medication use with a $\mathrm{BP}>130 / 80$ in a diabetic or $>140 / 90$ in a non-diabetic patient on the most recent measurement. Hyperlipidemia was defined as use of lipid-lowering medication or by the most recent lipid values exceeding treatment criteria of the Canadian Cardiovascular Society.

RESULTS: Charts of 75 patients were reviewed. Mean age was $52 \pm 14$ (SD) years with the mean transplant duration $67 \pm 57$ months. $8 \%$ of patients were obese. Prevalence of diabetes was $27 \%$. Of the patients with diabetes, $40 \%$ did not meet criteria for diabetes control. $61 \%$ of patients met criteria for hypertension, with $52 \%$ of these patients on antihypertensive medications. Of the patients receiving antihypertensive medication, $46 \%$ had uncontrolled hypertension. $42 \%$ of patients were classified as hyperlipidemic, with $52 \%$ of hyperlipidemic patients on lipid-lowering medication. Of the patients receiving lipid-lowering medication, $35 \%$ were hyperlipidemic.

CONCLUSIONS: Important cardiovascular risk factors were prevalent in this post-transplant population, and control was suboptimal. With progressive improvements in survival following lung transplantation, the importance of cardiovascular mortality and morbidity will continue to increase. An aggressive approach to management of cardiovascular risk factors is essential to minimize risk.

\section{4}

ACID TREATMENT OF RAT LUNG PARENCHYMAL EXPLANTS RESULTS IN TGF- $\beta 1$ INDUCTION OF CONNECTIVE TISSUE SYNTHESIS: IMPLICATIONS FOR GASTROESOPHAGEAL REFLUX DISEASE (GERD) IN IDIOPATHIC PULMONARY FIBROSIS (IPF)

Y Xu, D O'Connor, M Kwan, G Raghu, $\underline{N}$ Khalil

The University of British Columbia and the Vancouver Coastal Health Research Institute, Vancouver, British Columbia; University of Washington, Seattle, Washington, USA

RATIONALE: IPF is the most common fibrotic lung disease and IPF is progressive, uniformly lethal, with no recognized etiology, or known effective treatment. It has been demonstrated that up to $87 \%$ of patients with IPF have GERD and that treatment of GERD resulted in a stable clinical course for 2-6 years. The association of increase in GERD with IPF suggests a pathogenic mechanism.

METHODS: Lungs of rats were lavaged and the vasculature infused with saline to remove all inflammatory cells, $5 \mu \mathrm{m}$ slices of lung were cultured with $\mathrm{HCl}$ ( $\mathrm{pHs} 1.0-3.0$ ) for 5,10 , and 20 minutes in the absence or presence of anti-TGF- $\beta 1$ antibodies. ELISA was used to quantitate the TGF- $\beta 1$ in conditioned media (CM). The remaining lung tissue was obtained 1, 4 and 7 days after exposure and subjected to Western analysis for connective tissue expression and pSmad-3 and connective tissue growth factor (CTGF) as markers of response to TGF- $\beta 1$.

RESULTS: CM from lung explants that received no treatment contained no biologically active TGF- $\beta 1$ but after 10 minutes of $\mathrm{HCl}(\mathrm{pH} \mathrm{1.0)}$ $9.3 \pm 2.1 \mathrm{pg} / \mathrm{ml}$ of TGF- $\beta 1$ was found in the CM $(\mathrm{p}<0.001)$. There was induction of collagen I, III and fibronectin $(p<0.001-0.01)$, CTGF $(\mathrm{p}<0.03)$, and $\mathrm{pSmad}-3(\mathrm{p}<0.03)$. In the presence of anti-TGF- $\beta 1$ antibody, the expression of connective tissue as well as CTGF and pSmad-3 were diminished. The increased expression of connective tissue proteins was observed up to 7 days after a single exposure to $\mathrm{HCl}$.

CONCLUSION: Gastroesophageal reflux of acidic material in patients with IPF may contribute to pulmonary fibrosis regulated by the release of active TGF- $\beta 1$.

Funding: BC Lung Association

\section{5}

SHORT PEPTIDES OF THE THROMBOSPONDIN-1 (TSP-1) RECEPTOR, CD36, INHIBIT BLEOMYCIN INDUCED PULMONARY FIBROSIS (BPF)

$X$ Lui, $\mathbf{H}$ Behzad, $\underline{N}$ Khalil

The University of British Columbia and the Vancouver Coastal Health Research Institute, Vancouver, British Columbia

RATIONALE: TGF- $\beta 1$ is a potent fibrogenic cytokine when it is converted from its latent form (L-TGF- $\beta 1$ ) to its active form (TGF- $\beta 1$ ). In lung injury induced by bleomycin (Blm) the conversion of L-TGF- $\beta 1$ occurs when L-TGF- $\beta 1$ associates with thombospondin-1 (TSP-1) and the TSP1/L-TGF- $\beta 1$ complex localizes to TSP-1 receptor, CD36. Peptide from amino acids 93-110, a region of the CD36 ectodomain (CD36 93-110) prevented the release of active TGF- $\beta 1$, lung inflammation and fibrosis. The efficacy of shorter peptides within CD36 93-110 in inhibition of pulmonary inflammation and fibrosis was determined.

METHOD: Rats given intratracheally (IT) normal saline, or 1 unit/rat of $\mathrm{Blm}$, or Blm with $1.6 \mu \mathrm{g} / \mathrm{rat}$ with amino acids removed from the 93-110 sequence were weighed daily and the lungs were harvested 7 days after treatments. Alveolar inflammatory cells obtained by bronchoalveolar lavage were used for cell counts. ELISA was used to quantitate TGF- $\beta 1$ in BAL fluids. Lung tissue homogenates were used for Western analysis to detect expression of fibronectin, collagen I and III. In addition lung proteins were immunoprecipitated with anti-CD36 and subjected to Western analysis for TSP- 1 and TGF- $\beta 1$.

RESULTS: Compared to Blm treated rats, rat weights were improved in groups treated with shorter peptides at all time points. Numbers of cells in BAL fluids, active and total TGF- $\beta 1$ in BAL fluids was decreased in the peptide treated groups. Blm treatment increased lung expression of connective tissue proteins, TSP-1 and CD36 but treatment with CD36 peptides greatly reduced expression of these proteins.

CONCLUSION: Shorter sequences of amino acids may be of therapeutic benefit in the treatment of pulmonary fibrosis such as in idiopathic pulmonary fibrosis.

Sponsor: CIHR-POP2, NRC-IRAP, Pacific Therapeutics Inc.

\section{6}

SUCTIONING THE ADULT PATIENT: A SYSTEMATIC REVIEW UPDATE

T] Overend ${ }^{1,2}$, CM Anderson ${ }^{2}$, D Brooks ${ }^{3}$, LC Cicutto ${ }^{3}$, M Keim $^{4}$, D McAuslan $^{2}$, ML Nonoyama $^{3}$

${ }^{1}$ University of Western Ontario; ${ }^{2}$ London Health Sciences Centre, London; ${ }^{3}$ University of Toronto, Toronto; ${ }^{4}$ St Joseph's Health Care, London, Ontario

RATIONALE: Suctioning is integral to patient care in numerous clinical settings, including patients on mechanical ventilation, and is practiced by many members of the health care team. Ensuring an evidence-based approach to the care of patients requiring suctioning is vital to the provision of best practice. The purpose of this systematic review (SR) was to assess literature on suctioning in adult patients, published since a previous clinical practice guideline (2001).

METHODS: A primary search was conducted of Medline (from 1998), and CINAHL, Embase, and Cochrane Library (all from 1996) electronic databases until September 2007. The dates reflect the search limits reached in the previous clinical practice guideline. A secondary search of reference lists of retrieved articles was also carried out. Two reviewers independently appraised each study before meeting to reach consensus. Study quality was evaluated using the Jadad and PEDro scales. Where sufficient data were available, meta-analysis was conducted using a random effects model. Where no comparisons were possible, qualitative analyses of the data was completed.

RESULTS: Eighty-six studies were critically appraised from 338 papers identified by the search strategy. Meta-analysis was possible only for open vs closed suctioning. Recommendations from 2001 with respect to hyperoxygenation, hyperinflation, use of a ventilator circuit adaptor, and subglottic suctioning were confirmed. Conclusions from the new body of literature were made with respect to indications for suctioning, open vs closed suction systems, use of drugs, and infection control.

CONCLUSIONS: While new evidence remains varied in strength, and is still lacking in many areas of suctioning practice, the evidence base for this treatment technique has increased since 2001.

Financial support: Physiotherapy Research Foundation of Canada 


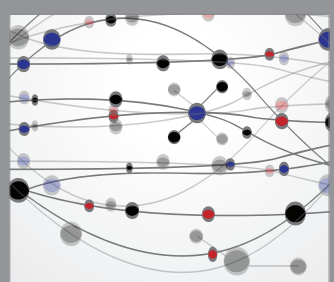

The Scientific World Journal
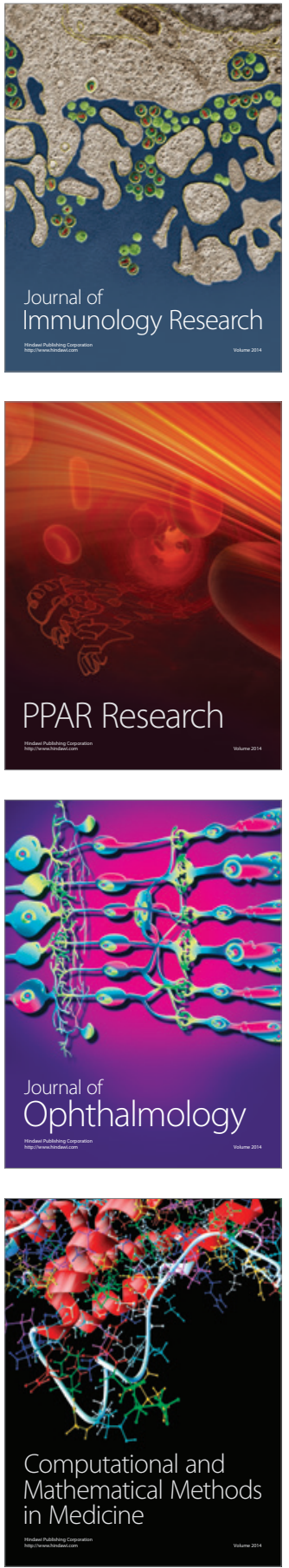

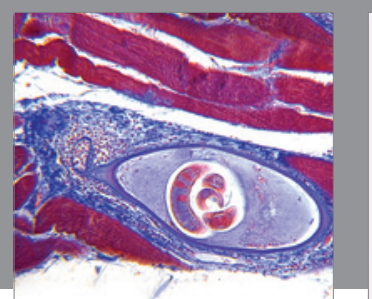

Gastroenterology Research and Practice

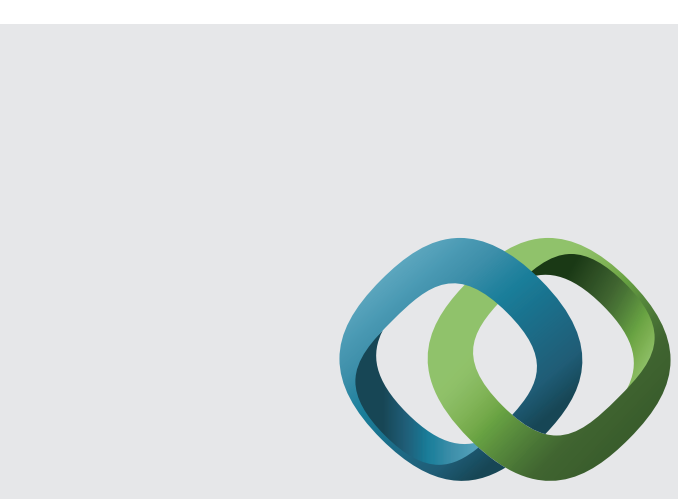

\section{Hindawi}

Submit your manuscripts at

http://www.hindawi.com
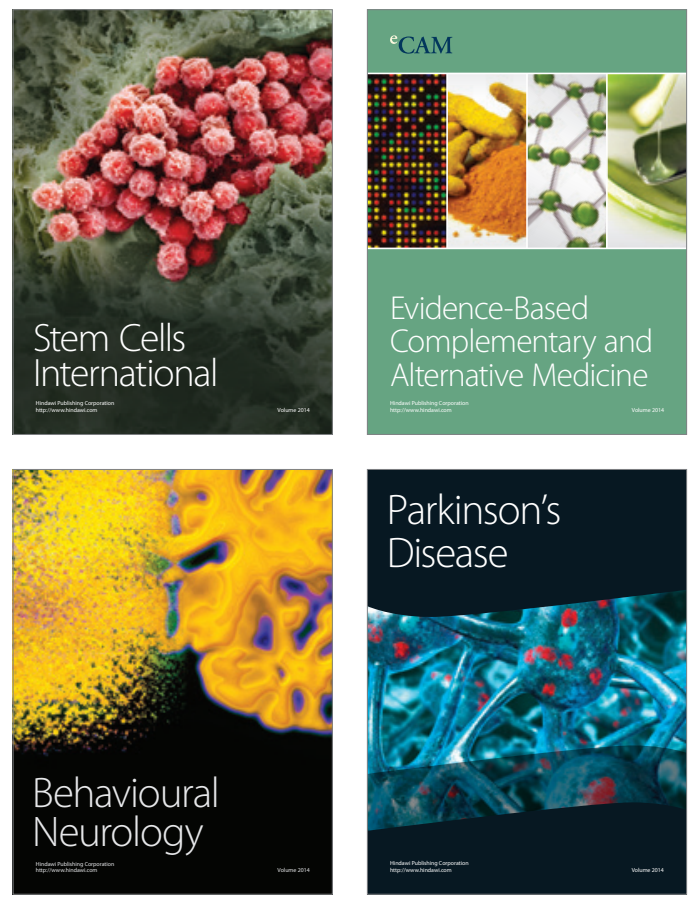
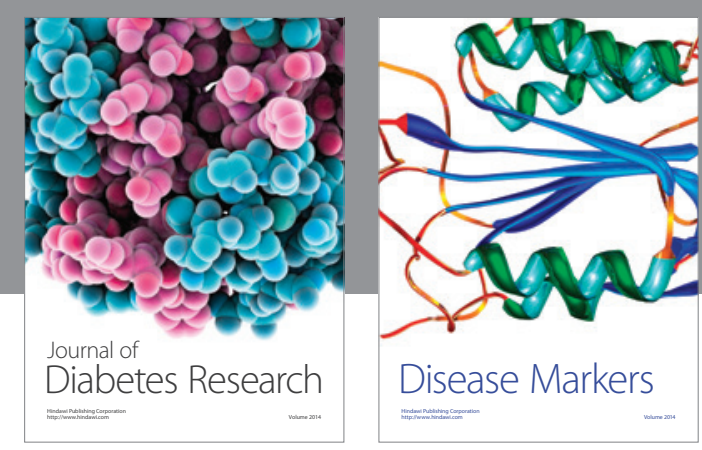

Disease Markers
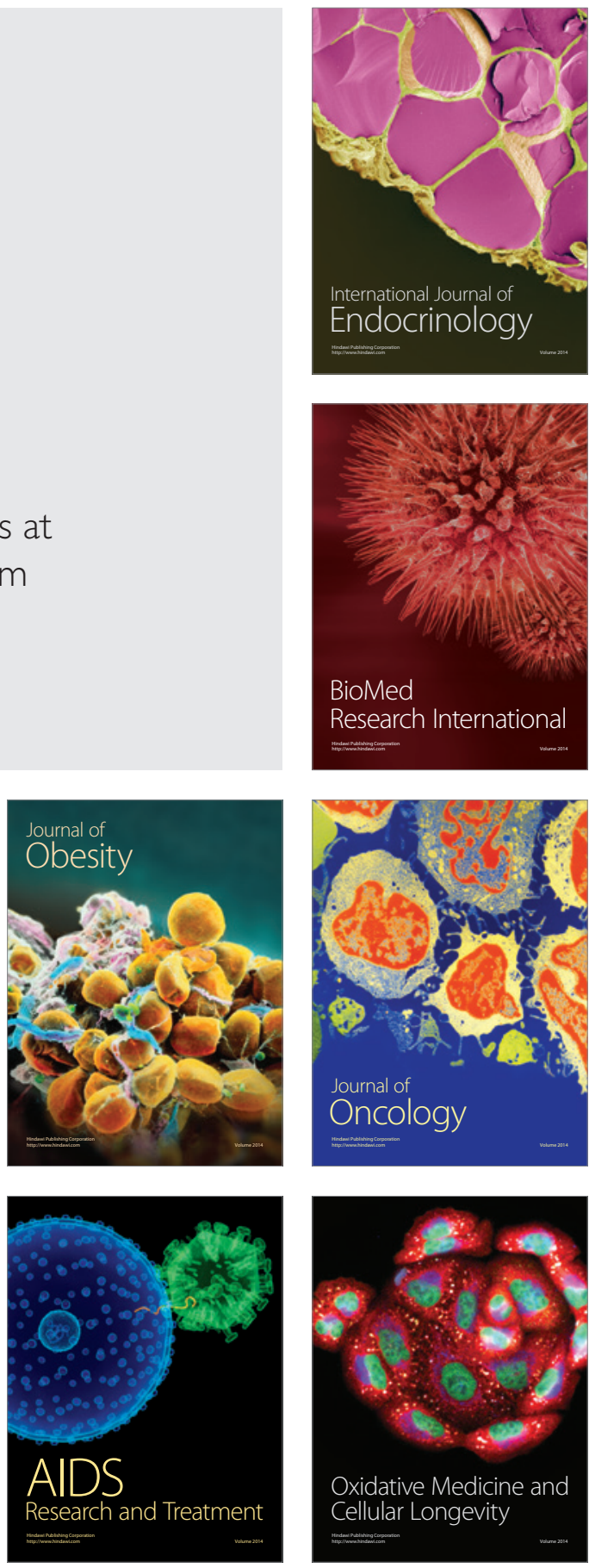